Article

\title{
Very-High-Cycle Fatigue and Charpy Impact Characteristics of Manganese Steel for Railway Axle at Low Temperatures
}

\author{
Byeong-Choon Goo ${ }^{1, *(D)}$, Hyung-Suk Mun ${ }^{2}$ and In-Sik $\mathrm{Cho}^{3}$ \\ Advanced Railroad Vehicle Division, Korea Railroad Research Institute, Uiwang 16105, Korea \\ 2 New Transportation Innovative Research Center, Korea Railroad Research Institute, Uiwang 16105, Korea; \\ hsmun@krri.re.kr \\ 3 Department of Advanced Materials Engineering, Sun Moon University, Asan 31460, Korea; \\ mbrosia@naver.com \\ * Correspondence: bcgoo@krri.re.kr; Tel.: +82-31-460-5243
}

Received: 29 June 2020; Accepted: 21 July 2020; Published: 22 July 2020

Featured Application: This work can be applied to the development of new axle materials and to the high-cycle fatigue testing of materials at low temperatures.

\begin{abstract}
Railway vehicles are being exposed with increasing frequency to conditions of severe heat and cold because of changes in the climate. Trains departing from Asia travel to Europe through the Eurasian continent and vice versa. Given these circumstances, the mechanical properties and performance of vehicle components must therefore be evaluated at lower and higher temperatures than those in current standards. In this study, specimens were produced from a commercial freight train axle made of manganese steel and subjected to high-cycle fatigue tests at $-60,-30$, and $20^{\circ} \mathrm{C}$. The tests were conducted using an ultrasonic fatigue tester developed to study fatigue at low temperatures. Charpy impact testing was performed over the temperature range of -60 to $60{ }^{\circ} \mathrm{C}$ to measure the impact absorption energy of the axle material. The material showed a fatigue limit above 2 million cycles at each temperature; the lower the test temperature, the greater the fatigue limit cycles. The impact absorption energy at $-60{ }^{\circ} \mathrm{C}$ was $81 \%$ less compared to the value at $20^{\circ} \mathrm{C}$. The axle material became completely brittle in the temperature range of -30 to $-40{ }^{\circ} \mathrm{C}$.
\end{abstract}

Keywords: railway axle; very-high-cycle fatigue; low temperature; Charpy impact test; microstructure; ultrasonic fatigue test; manganese steel

\section{Introduction}

With recent changes in climate, railroad vehicles are now operating in a wider range of conditions than in the past, including deep cold and heatwaves. Under such circumstances, the dynamic characteristics of the vehicle may be changed, and unexpected failures may occur [1,2]. For these reasons, interest in the mechanical properties of components at low and high temperatures is increasing. The axle is one of the key components affecting the structural safety of rolling stock. The failure of an axle can lead to the derailment of a vehicle, fatal accidents, property loss, etc. When flying ice cubes by train gust or gravel on the track impact the axle, a defect may occur on the surface of the axle [3]. Cracks may grow from the defect and lead to the axle breaking. So, in addition to fatigue strength, resistance to shock is one of the required standards of axles [4,5]. The fatigue strength and the impact resistance of a material depend on temperature, but the Korean standard [5] does not specify the temperature during tests. In general, railway vehicles are designed to have long lifetimes, from 20 to more than 40 years. Their components need to have long durability. During the lifetime of a railway 
vehicle, which is typically $3 \times 10^{6} \mathrm{~km}$, an axle installed on the vehicle experiences very high cycles of fatigue loading (1.0 1.2 giga-cycles). However, the giga-cycle fatigue properties of axles have not been studied much because of the restrictions of testing time and costs. In the past, conducting fatigue tests in the giga-cycle range was not easy. Even when a fatigue test is performed at $100 \mathrm{~Hz}$ without rest, 115 days are needed to apply $10^{9}$ loading cycles. Therefore, components under fatigue loading have been designed by using an S-N (stress-number of cycles to failure) curve, with an endurance limit of $2 \times 10^{6}$ cycles. However, according to the results of very-high-cycle fatigue tests, the fatigue strength of some materials decreases as the loading cycles increase above $2 \times 10^{6}$ cycles. In other words, fatigue limits were not observed for those materials. Under these circumstances, studies on fatigue characteristics at very high cycles are required.

High-cycle fatigue testing technologies were widespread in the early 2000s [6-8] with the advent of new technologies such as ultrasonic resonance fatigue testing. Ultrasonic fatigue specimens have a cylindrical or rectangular cross section. Specimen dimensions can be calculated by solving the elastic wave equations [6,7]. In general, a $20 \mathrm{kHz}$ ultrasonic transducer is widely used. Most tests are performed under tension-compression loading. Stanzl-Tschegg et al. [9], Bathias [10], and Nikitin et al. [11] presented test machines for torsional ultrasonic fatigue tests. Recently, fatigue specimens have been designed and studied under simultaneous tensile and shear stress [12,13].

Wang et al. [14] compared the fatigue behavior of two spring wires for automobile use $(\mathrm{CrV}$ and $\mathrm{CrSi}$ ) under a giga-cycle regime. The $\mathrm{CrV}$ steel showed constant fatigue strength over $10^{6}$ cycles, which means that this material has a fatigue limit. However, the $\mathrm{CrSi}$ had decreasing fatigue strength with loading cycles. In the case of fatigue life beyond $10^{7}$ cycles, fatigue cracks occurred from the defects in the interior of the specimens. According to their calculated results, the crack initiation life was more than $99 \%$ of the total fatigue life. In their other research [15] on ultra-high-strength steels, they found that high-cycle fatigue cracks initiated from subsurface inclusions of sulfides. Ochi et al. [16] presented similar results with high-strength steels SUJ2 (high-carbon-chromium bearing steel) and SNCM439 (nickel chromium molybdenum steel). The fatigue strengths decreased over $10^{7}$ cycles. In the short life regime, fatigue cracks started from the surface. In the high-cycle regime, fatigue cracks occurred from internal defects or nonmetallic inclusions such as $\mathrm{TiN}, \mathrm{Al}_{2} \mathrm{O}_{3}, \mathrm{MnS}$, and $\mathrm{Al}_{2} \mathrm{O}_{3}$. The effect of nonmetallic inclusions on the fatigue strength of high-strength steels was studied by Murakami and Endo [17] and by Murakami et al. [18]. They expressed fatigue strength as a function of Vickers hardness, stress ratio, and the root of the projected area of inclusion. Most studies have focused on high-strength steels or alloys with hardening heat treatment. However, the railway axle material in this study is normalized and has a medium strength level (tensile strength $590 \mathrm{MPa}$ ), and it does not contain $\mathrm{Cr}, \mathrm{Mo}, \mathrm{Ni}, \mathrm{Cu}$, etc. It is composed of five elements (C, Mn, Si, S, P) and Fe. Whether this kind of manganese steel has a fatigue limit or not is interesting. Zettl et al. [19] investigated the giga-cycle fatigue behavior of normalized carbon steel ( $\mathrm{Ck} 15$, tensile strength $418 \mathrm{MPa})$ using an ultrasonic fatigue tester. The chemical composition of the material is $0.15 \mathrm{wt} \% \mathrm{C}, 0.45 \mathrm{Mn}, 0.20 \mathrm{Si}, \mathrm{P}, \mathrm{S}$, Fe balance. All fatigue cracks initiated at surfaces. The fatigue strength decreased until $10^{7}$ cycles; after that, it was nearly constant. The fatigue strength at $10^{9}$ cycles was $2.5 \%$ lower than at $10^{7}$ cycles. The highest number of cycles to failure was $1.3 \times 10^{7}$ cycles. Zhao et al. [20] carried out fatigue tests in a giga-cycle regime using specimens produced from a real axle with chemical composition $\mathrm{C}, \mathrm{Si}, \mathrm{Mn}, \mathrm{Cr}, \mathrm{Ni}, \mathrm{Cu}, \mathrm{Al}$, and Fe. A duplex S-N curve (inclined-horizontal-inclined-horizontal curve) was obtained. All cracks initiated at surfaces. Damaged spots around subsurface inclusions that occurred during production were observed, but did not propagate beyond a certain size.

Qian et al. [21] compared the fatigue strengths of structural steel $40 \mathrm{Cr}(0.4 \% \mathrm{C}, 1 \% \mathrm{Cr})$ in air, fresh water, and $3.5 \% \mathrm{NaCl}$ aqueous solution. Specimens were tested to $2 \times 10^{9}$ cycles with a rotary bending machine. The S-N curves in air and in water showed inclined-horizontal-inclined shapes, but the $\mathrm{S}-\mathrm{N}$ curve in $\mathrm{NaCl}$ presented a continuously decreasing shape. According to the experimental results for $25 \mathrm{Cr} 2 \mathrm{Ni} 2 \mathrm{MoV}$ welded specimens by $\mathrm{Wu}$ et al. [22], the S-N curve at room temperature presented duplex slopes. However, at $370{ }^{\circ} \mathrm{C}$, the fatigue strength decreased continuously. The crack 
initiation mechanism was similar at both temperatures. Fatigue studies at high temperatures are numerous, but comparative studies on fatigue properties at room temperature and low temperatures for manganese steels are rarely found in the literature. The purpose of this study is to investigate the fatigue and impact characteristics at low and high temperatures in consideration of the actual operating environment of railway vehicles. Ultrasonic fatigue testing equipment capable of fatigue tests to $-160{ }^{\circ} \mathrm{C}$ was developed, and the fatigue and Charpy impact characteristics of the axle material were examined over a temperature range of -60 to $+60{ }^{\circ} \mathrm{C}$. Crack initiation and fracture surfaces were investigated.

\section{Materials and Methods}

The main chemical composition of the axle material is $\mathrm{C}, \mathrm{Si}, \mathrm{Mn}$, and Fe (Table 1). The specimens were obtained from a new railway vehicle commercial axle. The longitudinal direction of the specimen coincided with that of the axle. The surface was polished by lapping. Tensile tests were performed according to ASTM A370. The measured yield and tensile strengths of three cylindrical specimens of $\Phi 8.75$ were within the ranges of 392-440 and 656-698 MPa, respectively (Figure 1). Figure 2 presents a microstructural image. The material is composed of ferrite (black part) and pearlite (gray part). The pearlite has a variety of shapes. The distance between $\mathrm{Fe}_{3} \mathrm{C}$ layers in a pearlite grain is different for each grain. Figure 3a shows the fatigue test specimen and the sampling location of the specimen from the axle. The minimum and maximum diameters of the specimen were 4 and $16 \mathrm{~mm}$, respectively. The specimen was designed according to reference [7]. The stress and strain in the specimen were obtained from the elastic wave theory [7]. Natural vibration frequencies were obtained using ABAQUS software. The convergence of the solution was checked as the number of elements increased. The material properties listed in Table 2 were used for the simulation. The Young's modulus and Poisson's ratio of the specimen were measured according to ASTM 1876-01. Properties of the horn were taken from the literature. Figure 3 shows the natural modes of the specimen, the horn, and the assembly. The lateral displacement of the specimen in the middle of the hourglass section was zero, and the natural frequency was $19,784 \mathrm{~Hz}$. This frequency is close to the excitation frequency of the input generator, $20 \mathrm{kHz}$.

Table 1. Composition of the axle material (wt \%) [5].

\begin{tabular}{cccccccc}
\hline $\mathbf{C}$ & $\mathbf{S i}$ & $\mathbf{M n}$ & $\mathbf{P}$ & $\mathbf{S}$ & $\mathbf{O}$ & $\mathbf{H}$ & $\mathbf{F e}$ \\
\hline $0.35-0.48$ & $0.15-0.40$ & $0.40-0.85$ & $<0.035$ & $<0.040$ & $<40 \mathrm{ppm}$ & $2.5 \mathrm{ppm}$ & Balance \\
\hline
\end{tabular}

Table 2. Material properties used for the finite element simulation.

\begin{tabular}{ccccc}
\hline Part & Material & Density $\left.\mathbf{( k g} / \mathbf{m}^{\mathbf{3}}\right)$ & Young's Modulus (GPa) & Poisson's Ratio \\
\hline Specimen & Train axle & 7833 & 211.51 & 0.283 \\
Horn & Titanium alloy & 4300 & 110 & 0.36 \\
\hline
\end{tabular}

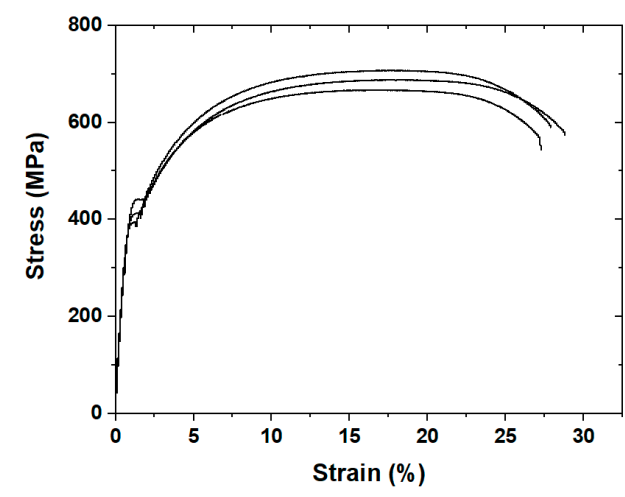

Figure 1. Tensile stress-strain curves. 


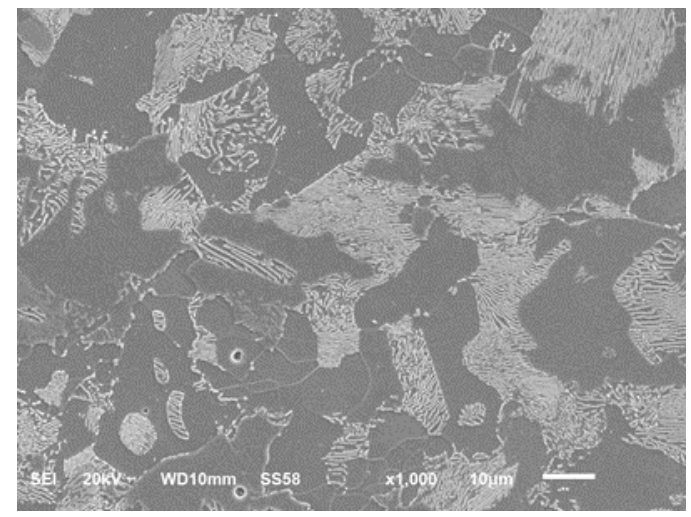

Figure 2. Microstructures of the axle material.

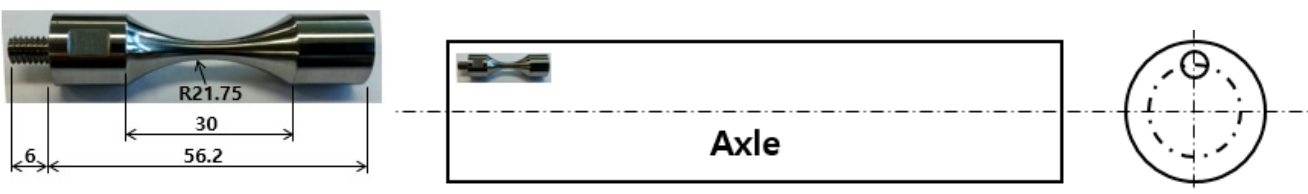

(a) Fatigue test specimen and sampling location from the axle.

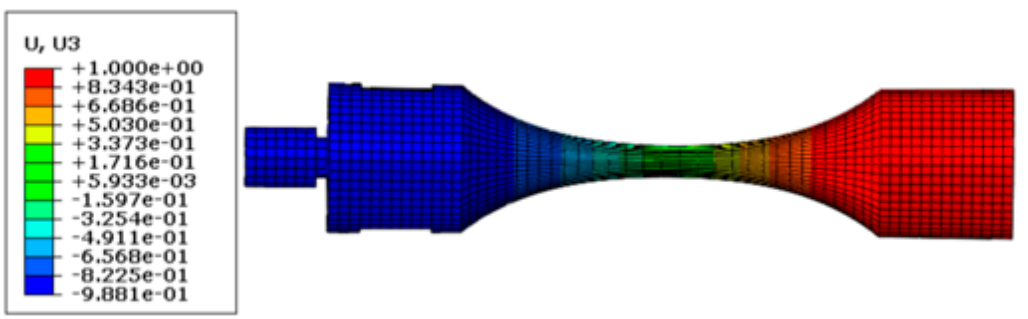

(b) Natural mode of the specimen, 19,551 Hz.

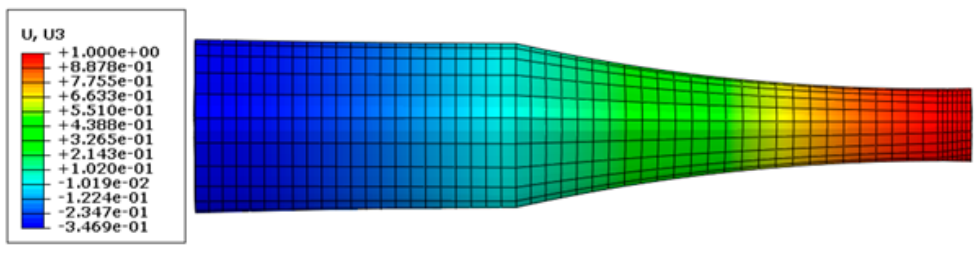

(c) Natural mode of the horn, 20,253 Hz.

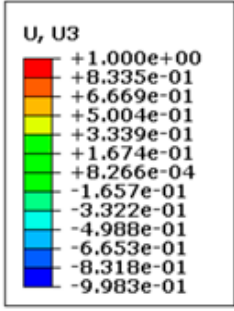

(d) Natural mode of the horn-specimen assembly, 19,784 Hz.

Figure 3. Modal analysis of the specimen and horn using the finite element method.

Figure 4 shows the newly developed piezoelectric UFT (ultrasonic fatigue test) equipment, which operates at a frequency of $20 \mathrm{kHz}$. The stress ratio ( $\mathrm{R}=\operatorname{minimum~load} / \mathrm{maximum}$ load $)$ was $\mathrm{R}=-1$. The UFT system consisted of a power generator, a converter (piezo actuator), and a horn attached mechanically to the converter by a screw. A personal computer controlled the generator 
and converter to impose a vibratory amplitude at the end of the horn. The power generator converts a $60 \mathrm{~Hz}$ voltage signal into a $20 \mathrm{kHz}$ sinusoidal ultrasonic electrical signal. The converter converts the $20 \mathrm{kHz}$ ultrasonic excitation signal into a mechanical signal. The boost and horn, with a natural frequency of $20 \mathrm{kHz}$, amplify the vibration. Displacement at the horn end was measured using a photonic sensor to calculate the stress value of the specimen. The stress value at the middle of the specimen was linearly proportional to the displacement of the specimen end and the dynamic modulus of elasticity of the specimen [6,7]. At $20 \mathrm{kHz}$, high-cycle fatigue testing generates excessive heat in the specimen, so countermeasures against heat generation are necessary. To ensure that the specimen was not heated, the test was performed by applying a load to the specimen for $0.3 \mathrm{~s}$ and stopping it for $3 \mathrm{~s}$. As a result, the increase of specimen temperature due to the deformation caused by the load was negligible. Several specimens were subjected to preliminary tests to confirm the variation of specimen temperature using an infrared camera. The low-temperature test condition was achieved by injecting liquid nitrogen into the chamber through a nozzle. The temperature of the chamber was controlled by opening and closing the nozzle. The resolution of temperature control was about $\pm 2{ }^{\circ} \mathrm{C}$. As shown in Figure 4 , the horn and the specimen were located in the chamber, in which a low temperature below $-160{ }^{\circ} \mathrm{C}$ could be realized. The developed equipment is expected to be useful for low-temperature fatigue testing.

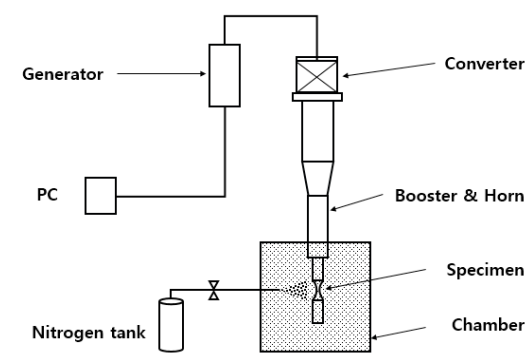

(a) Schematic diagram

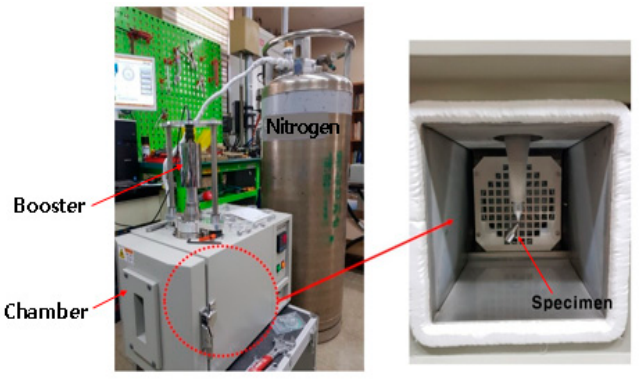

(b) Test equipment

Figure 4. Ultrasonic resonant fatigue test equipment.

Figure 5 shows a drawing and photograph of the Charpy impact test specimen. The specimens were produced according to ASTM A370 from a commercial railway vehicle axle. The surface was polished by lapping. The longitudinal direction of the specimen coincided with that of the axle. The specimen size was $10 \times 10 \times 55$ and a V-shaped notch was machined in its center. The Charpy impact test is performed by hitting the opposite side of the impact specimen fixed at both ends with a free-falling hammer. The test evaluates the impact resistance of a specimen by measuring the energy consumed when the impact specimen breaks. Under actual conditions, gravel or ice rubble on the tracks may be lifted by the wind generated by the vehicle and hit the axle, impacting the surface of the axle and creating surface defects. Impact resistance is proportional to the ability to resist crack propagation. Therefore, impact resistance is one of the key material specifications that ensure axle durability.

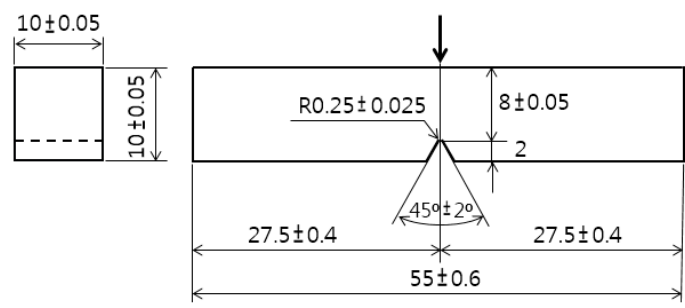

(a) Geometry of Charpy specimen

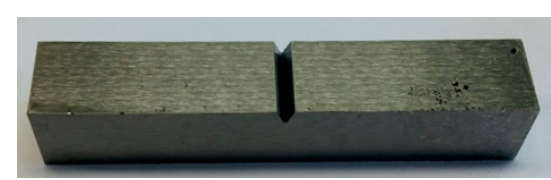

(b) Charpy impact specimen

Figure 5. Geometry and photograph of the Charpy impact specimen. 


\section{Results and Discussion}

\subsection{Fatigue Test}

Figure 6a presents an S-N diagram showing the fatigue test data at a room temperature of about $20{ }^{\circ} \mathrm{C}$. The logarithm of the number of cycles to failure is on the X-axis, and stress amplitude is on the Y-axis. When $200 \mathrm{MPa}$ stress amplitude was applied to the center of the specimen, fatigue failure did not occur until $10^{9}$ cycles, which means that the axle material had typical carbon steel properties with a fatigue limit. However, the fatigue limit was not $2 \times 10^{6}$ cycles. Some specimens fractured in the $2 \times 10^{6}$ to $1 \times 10^{7}$ cycle range. The fracture surfaces in Figure $6 \mathrm{~b}, \mathrm{c}$ show the fracture surfaces at 213,000 and $1.02 \times 10^{6}$ cycles, respectively. A crack occurred on the surface, gradually grew elliptically, and then reached an unstable state at a certain crack size. The specimen was finally broken. Some inclusions were found on the fracture surface. According to [1], inclusions found in axles are typically aluminates, sulfides, silicates, oxides, etc. The specification [4] specifies the acceptable size and quantity of inclusions.

Figure 7a presents an $\mathrm{S}-\mathrm{N}$ diagram at $-30^{\circ} \mathrm{C}$. Fatigue failure in four specimens occurred in the $2 \times 10^{6}$ to $1 \times 10^{7}$ cycle range, beyond the 2 million cycles traditionally regarded as the infinite life of steel. Figure $7 \mathrm{~b}$-e shows the fracture surfaces; cracks formed on the surface as in the room temperature case and gradually progressed. Once they reached a certain size, they entered an unstable growth mode. Some black voids or inclusions were observed on the fracture surface. Figure 8a presents an S-N diagram at $-60^{\circ} \mathrm{C}$. Similar to at $-30^{\circ} \mathrm{C}$, fatigue failure in five specimens occurred in the $2 \times 10^{6}$ to $1 \times 10^{7}$ cycle range, beyond the 2 million cycles. Figure 8b,c shows the fracture surfaces; cracks formed on the surface as in the room temperature case and gradually progressed. Once they reached a certain size, they entered an unstable growth mode. Some black voids or inclusions were observed on the fracture surface. Further, it was observed that long, white ridges were decreased in the stable crack propagation region. Figure 9 compares fatigue test data for $20,-30$, and $-60^{\circ} \mathrm{C}$. It can be seen that the fatigue strength increases with decreasing temperature.

In general, for metals, the lower the temperature, the higher the hardness, the tensile, and yield strengths. Fatigue strength is proportional to hardness and tensile strength. When the amplitude of the acting stress is $S_{a}$ and the number of cycles to failure under a given stress amplitude $\Delta S$ is $N$, the straight section of the $S_{a}-N$ diagrams at each temperature can be expressed as Equations (1)-(3). $\mathrm{R}$ is the coefficient of determination. The fatigue strengths at 2 million cycles for $+20,-30$, and $-60{ }^{\circ} \mathrm{C}$ were $210.1,225.2$, and $251.9 \mathrm{MPa}$, respectively. Fatigue strength at -30 and $-60{ }^{\circ} \mathrm{C}$ increased by 7.1 and $19.9 \%$, respectively, compared to the fatigue strength at room temperature. Statistical analysis of the S-N curves was performed using the Excel program. The results are summarized in Table 3.

$$
\begin{aligned}
& +20{ }^{\circ} \mathrm{C}: \mathrm{S}_{\mathrm{a}}=-25.786 \log (\mathrm{N})+372.57, \mathrm{R}^{2}=0.895 \\
& -30{ }^{\circ} \mathrm{C}: \mathrm{S}_{\mathrm{a}}=-28.946 \log (\mathrm{N})+407.61, \mathrm{R}^{2}=0.931 \\
& -60{ }^{\circ} \mathrm{C}: \mathrm{S}_{\mathrm{a}}=-34.207 \log (\mathrm{N})+467.43, \mathrm{R}^{2}=0.888
\end{aligned}
$$

Table 3. Statistical analysis of the S-N curves.

\begin{tabular}{cccc}
\hline & Coefficient of Determination & Standard Deviation & Standard Error of the Mean \\
\hline$+20{ }^{\circ} \mathrm{C}$ & 0.895 & 27.95 & 6.58 \\
\hline$-30{ }^{\circ} \mathrm{C}$ & 0.931 & 20.03 & 5.78 \\
\hline$-60^{\circ} \mathrm{C}$ & 0.888 & 36.19 & 10.44 \\
\hline
\end{tabular}




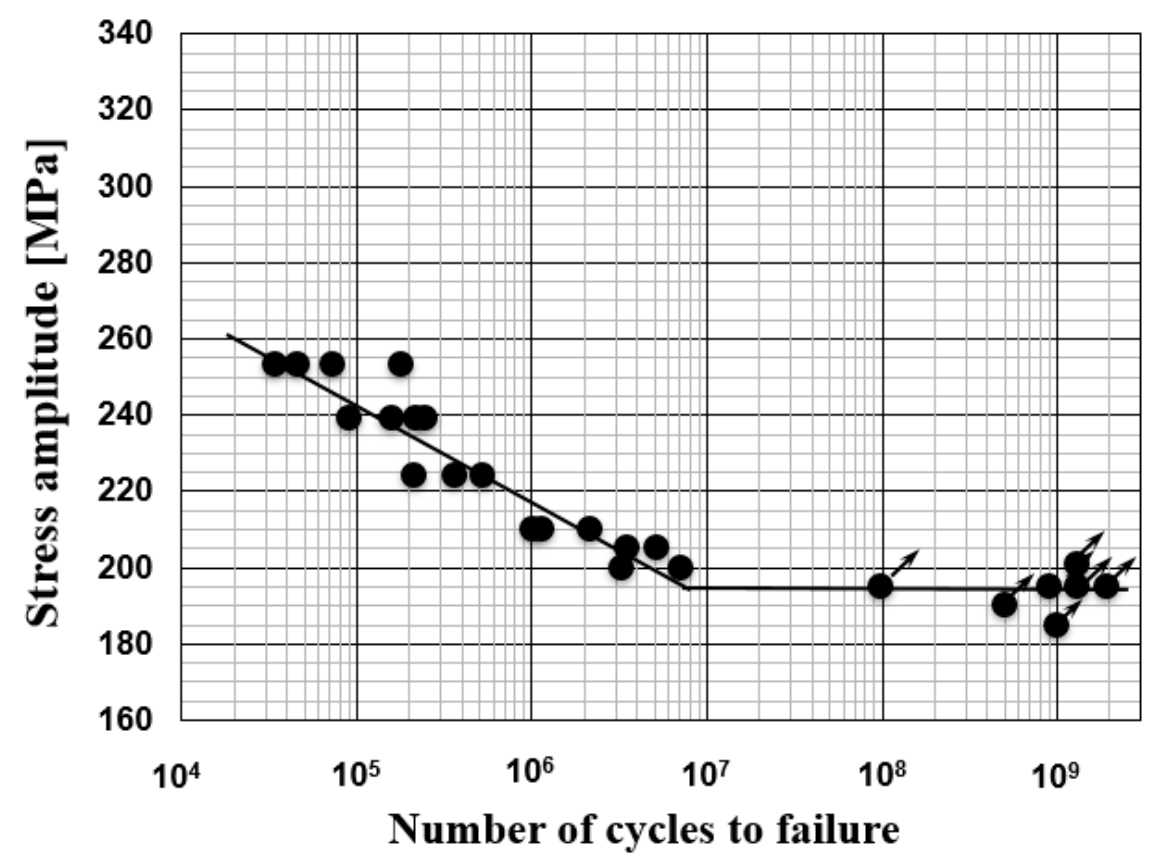

(a) S-N diagram at room temperature.

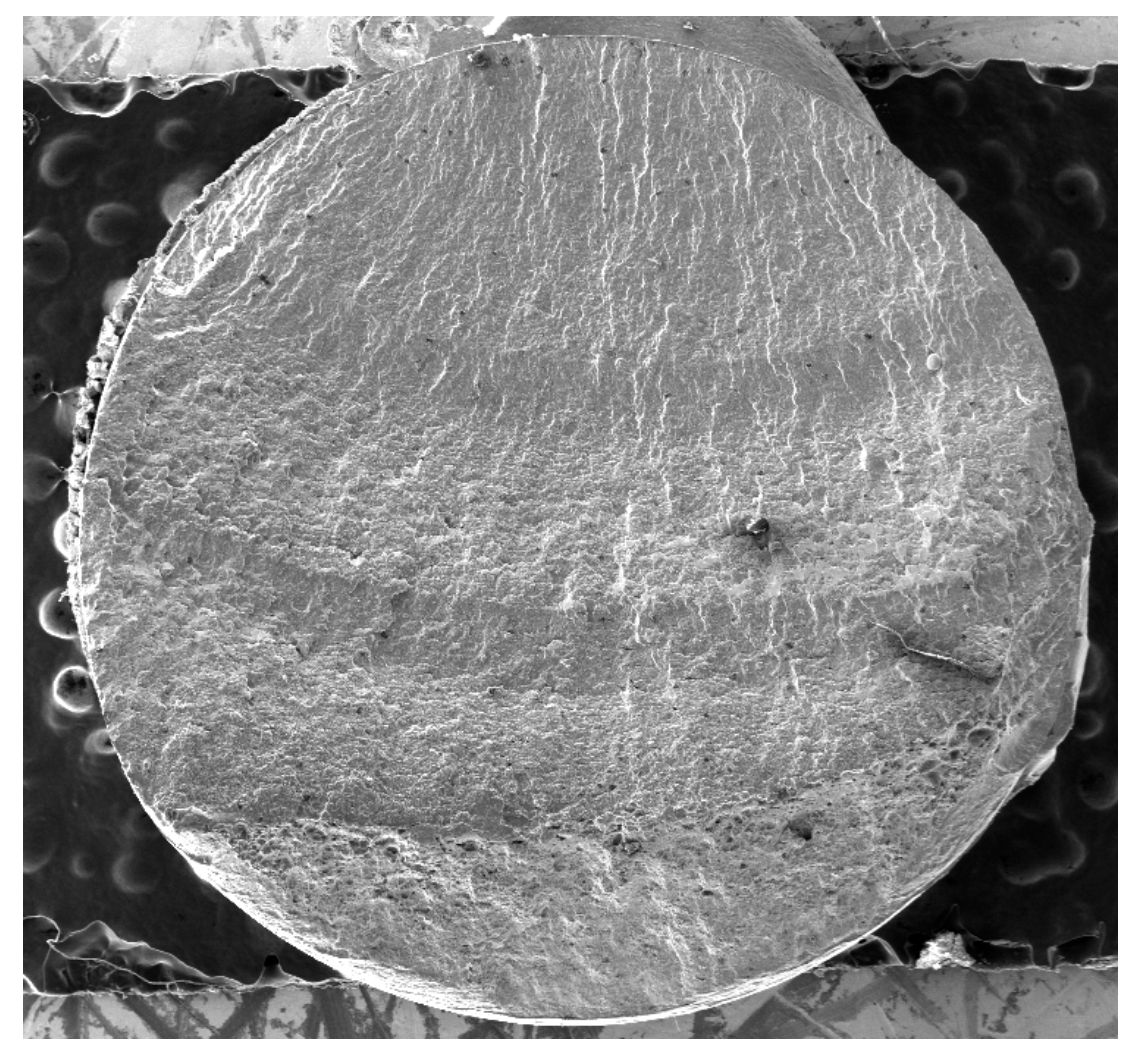

(b) Fracture surface at room temperature, $224 \mathrm{MPa}, 213,000$ cycles.

Figure 6. Cont. 


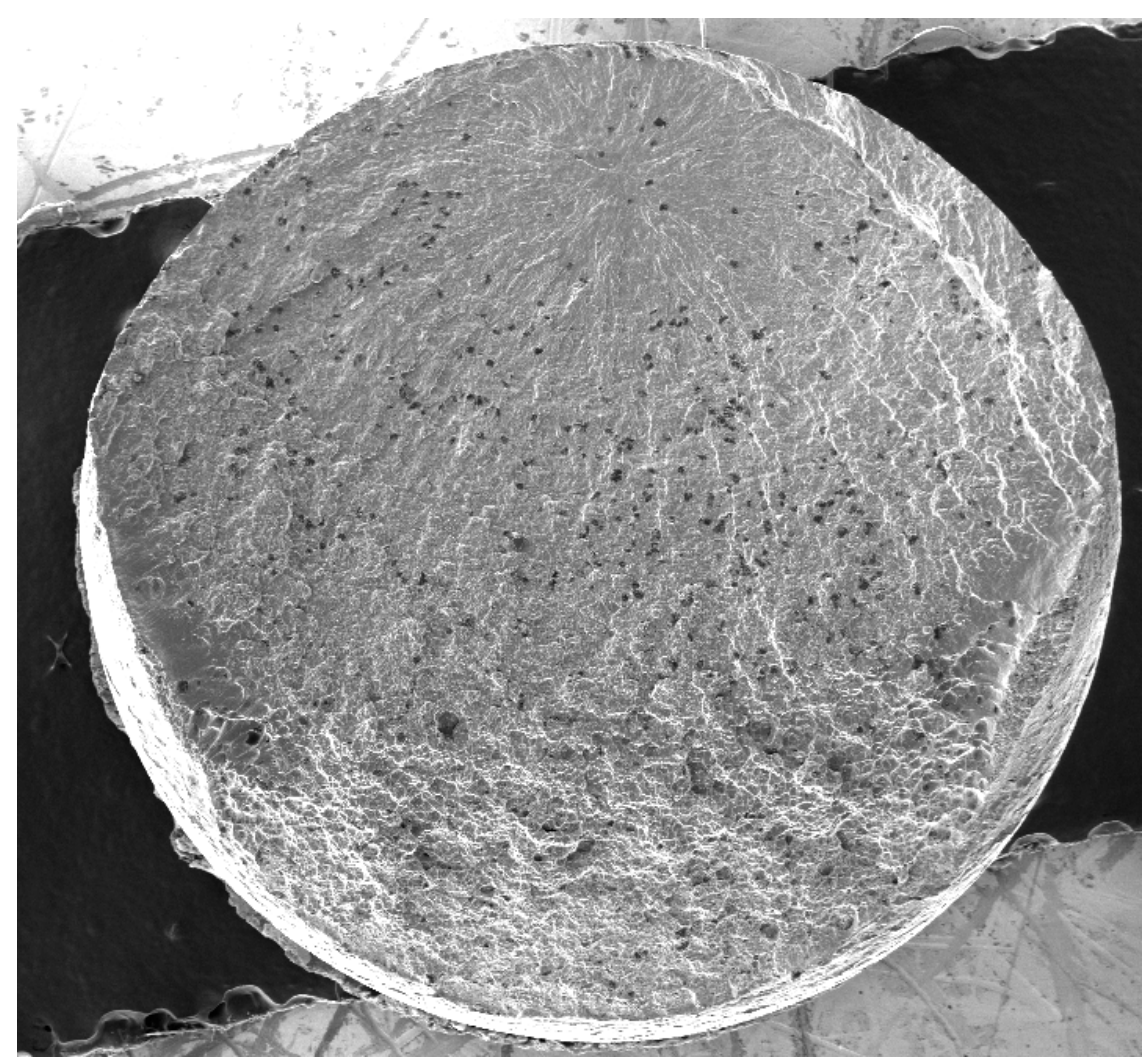

(c) $210 \mathrm{MPa}, 1.02 \times 10^{6}$ cycles.

Figure 6. S-N diagram and fracture surface at room temperature.

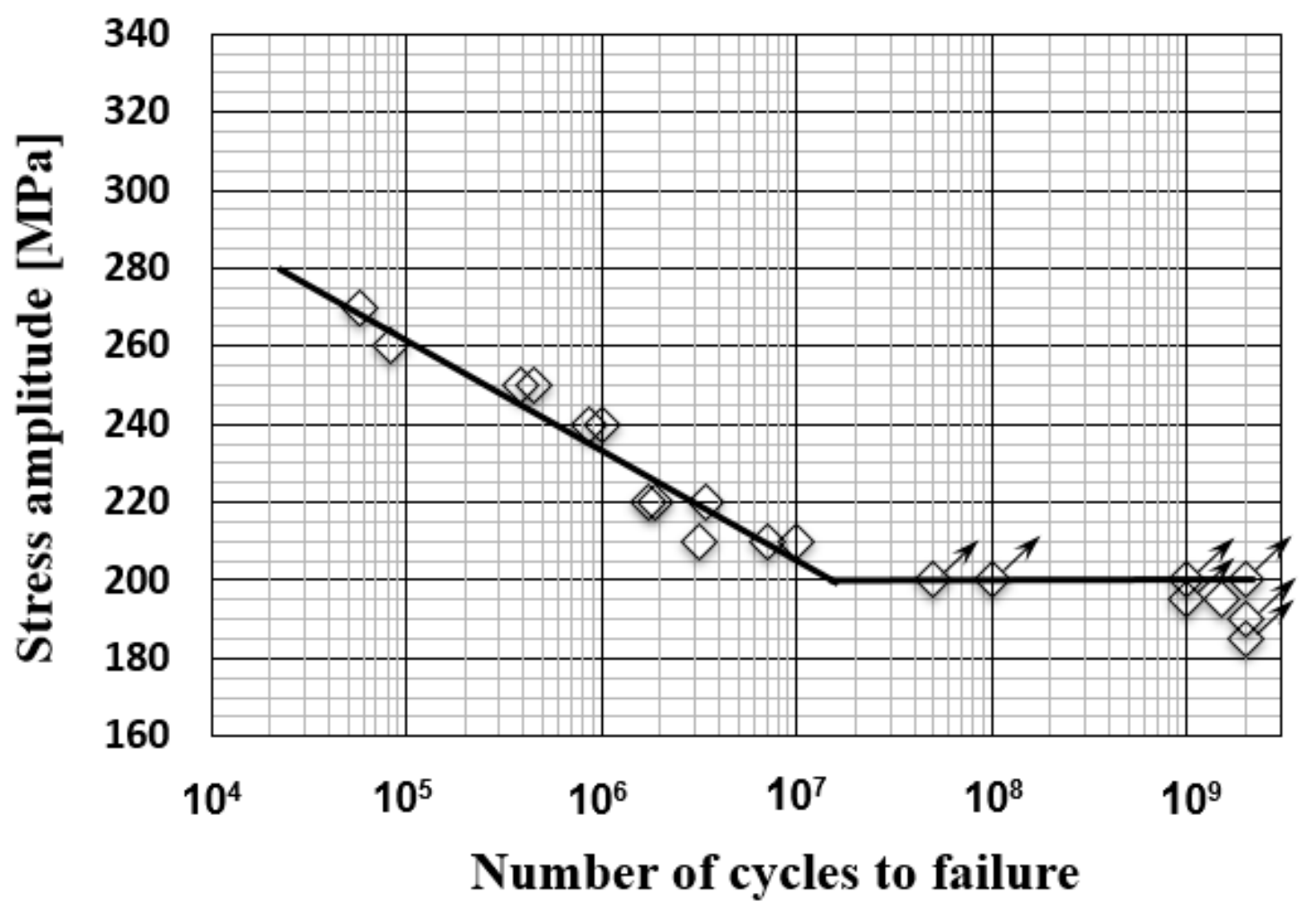

(a) S-N diagram at $-30^{\circ} \mathrm{C}$.

Figure 7. Cont. 


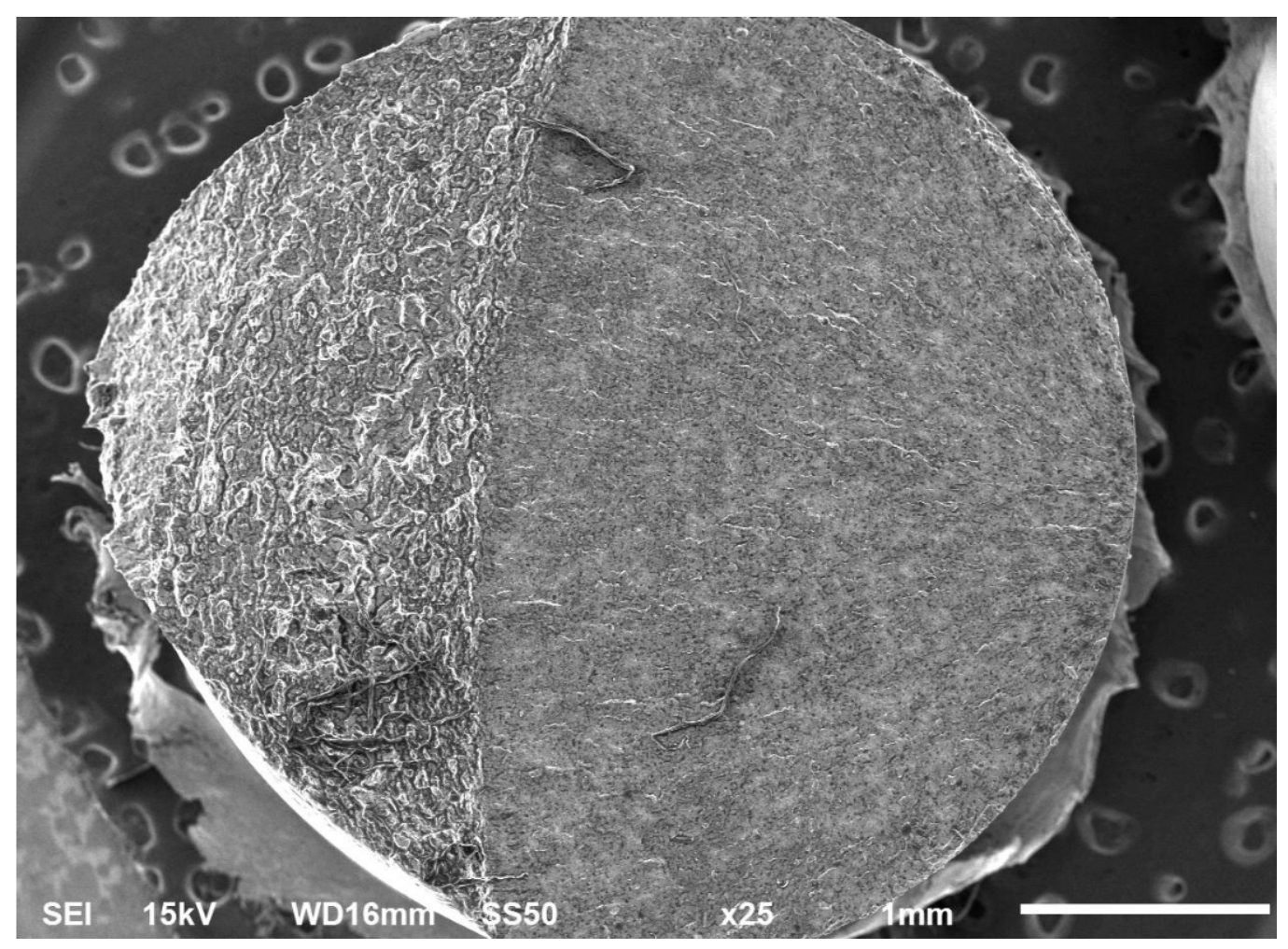

(b) Fracture surface at $-30^{\circ} \mathrm{C}, 240 \mathrm{MPa}, 854,000$ cycles.

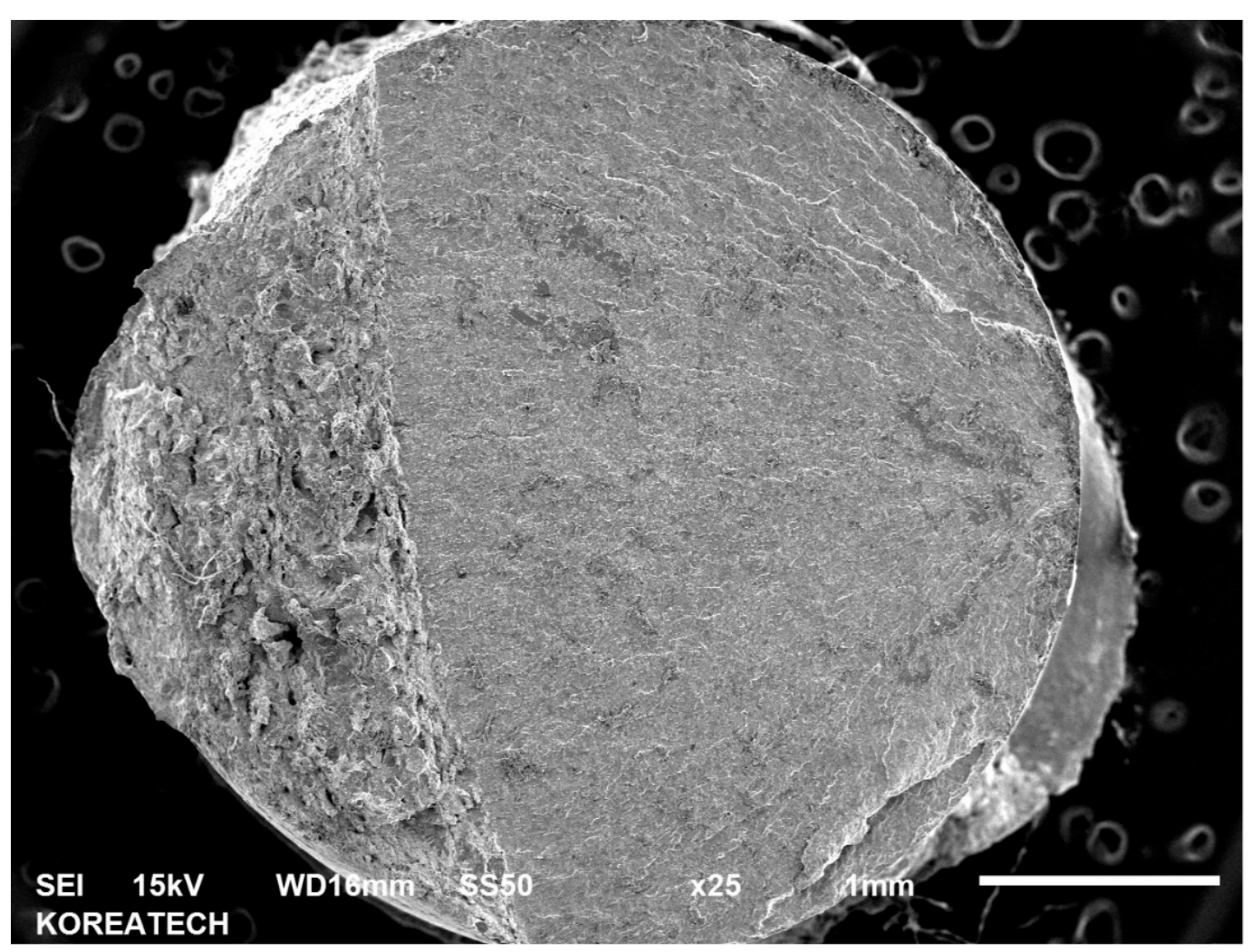

(c) Fracture surface at $-30^{\circ} \mathrm{C}, 220 \mathrm{MPa}, 3.46 \times 10^{6}$ cycles.

Figure 7. Cont. 


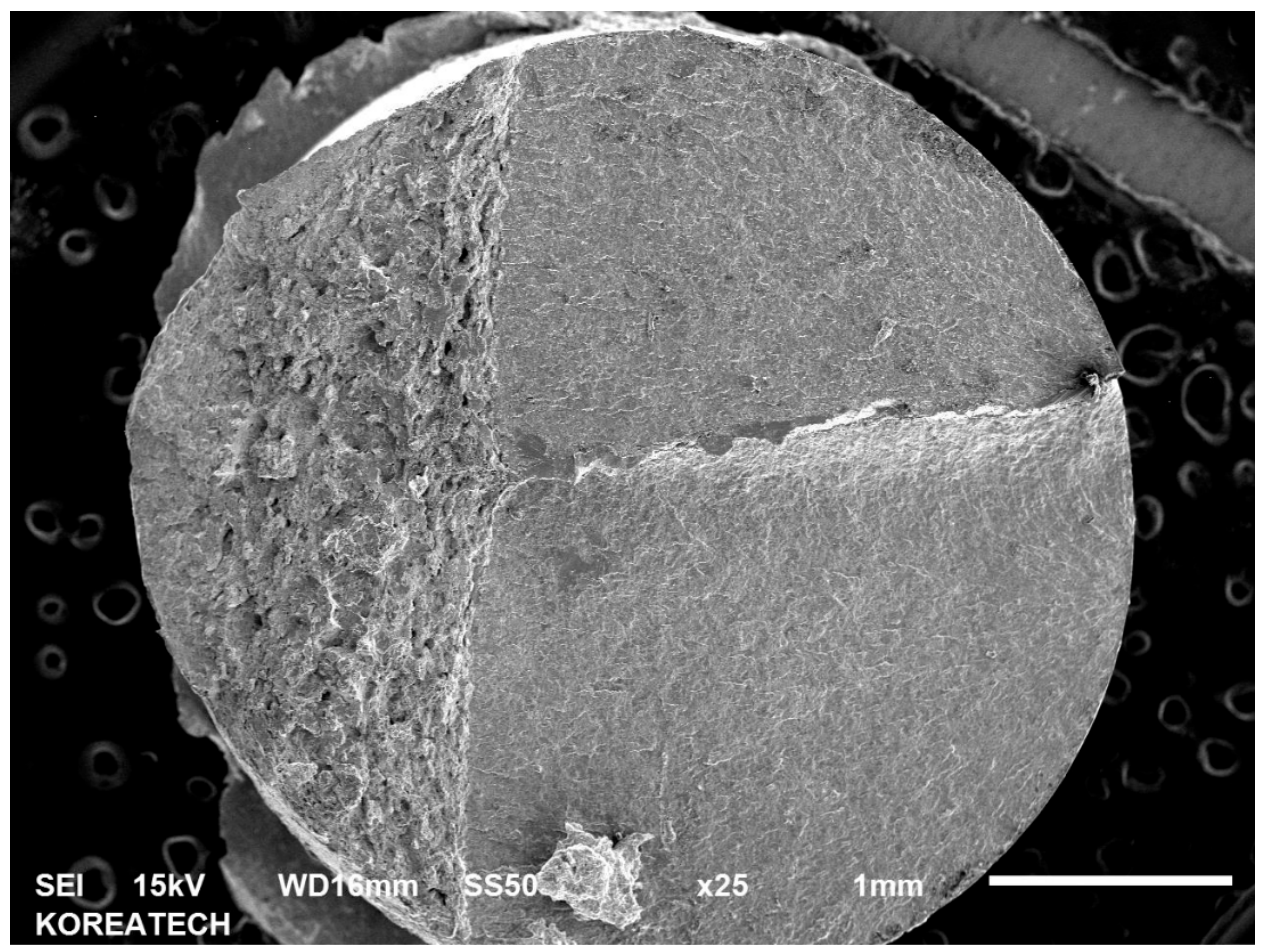

(d) Fracture surface at $-30^{\circ} \mathrm{C}, 210 \mathrm{MPa}, 7.12 \times 10^{6}$ cycles.

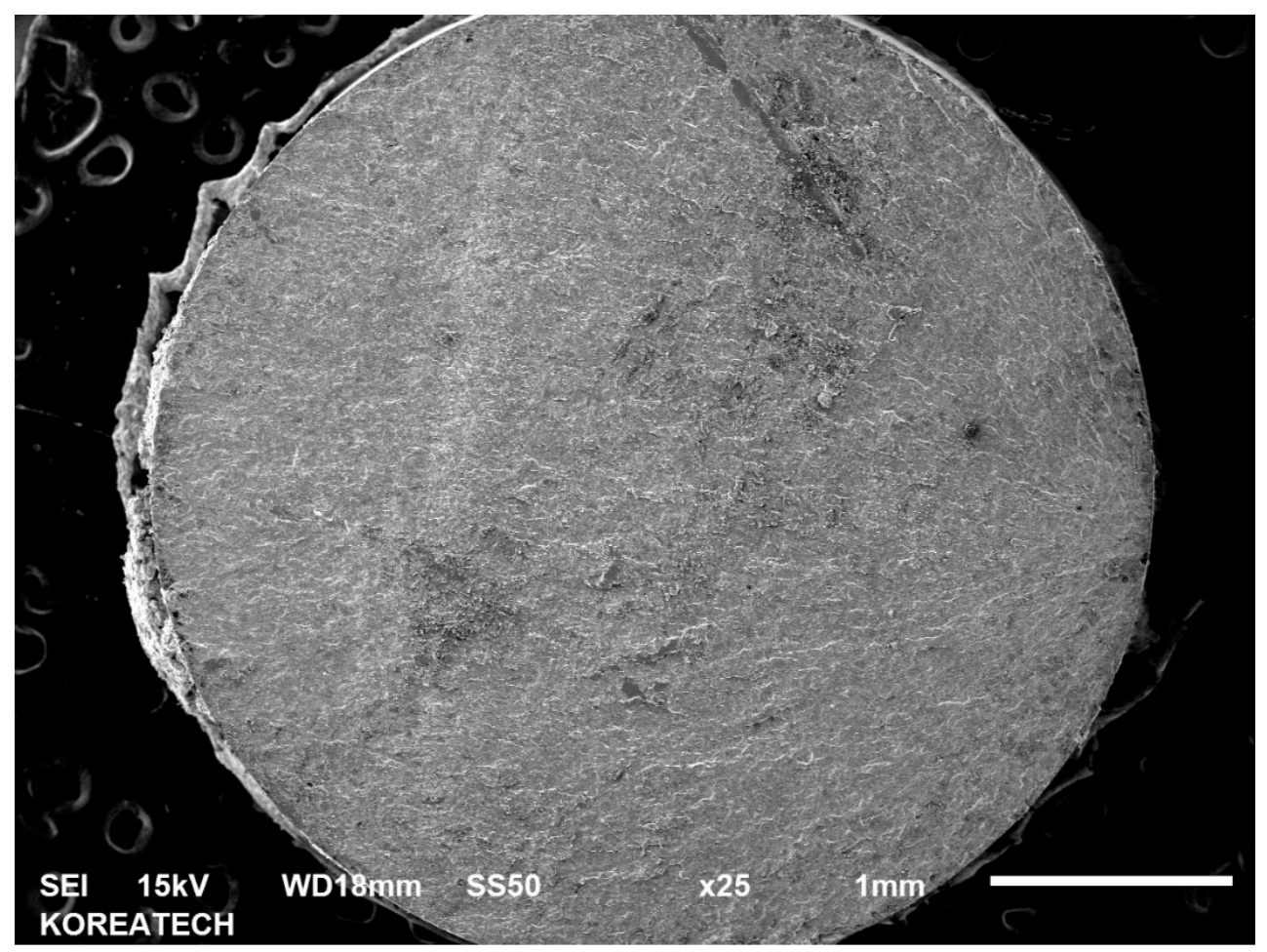

(e) Fracture surface at $-30^{\circ} \mathrm{C}, 200 \mathrm{MPa}, 10^{7}$ cycles.

Figure 7. S-N diagram and fracture surface at $-30{ }^{\circ} \mathrm{C}$. 


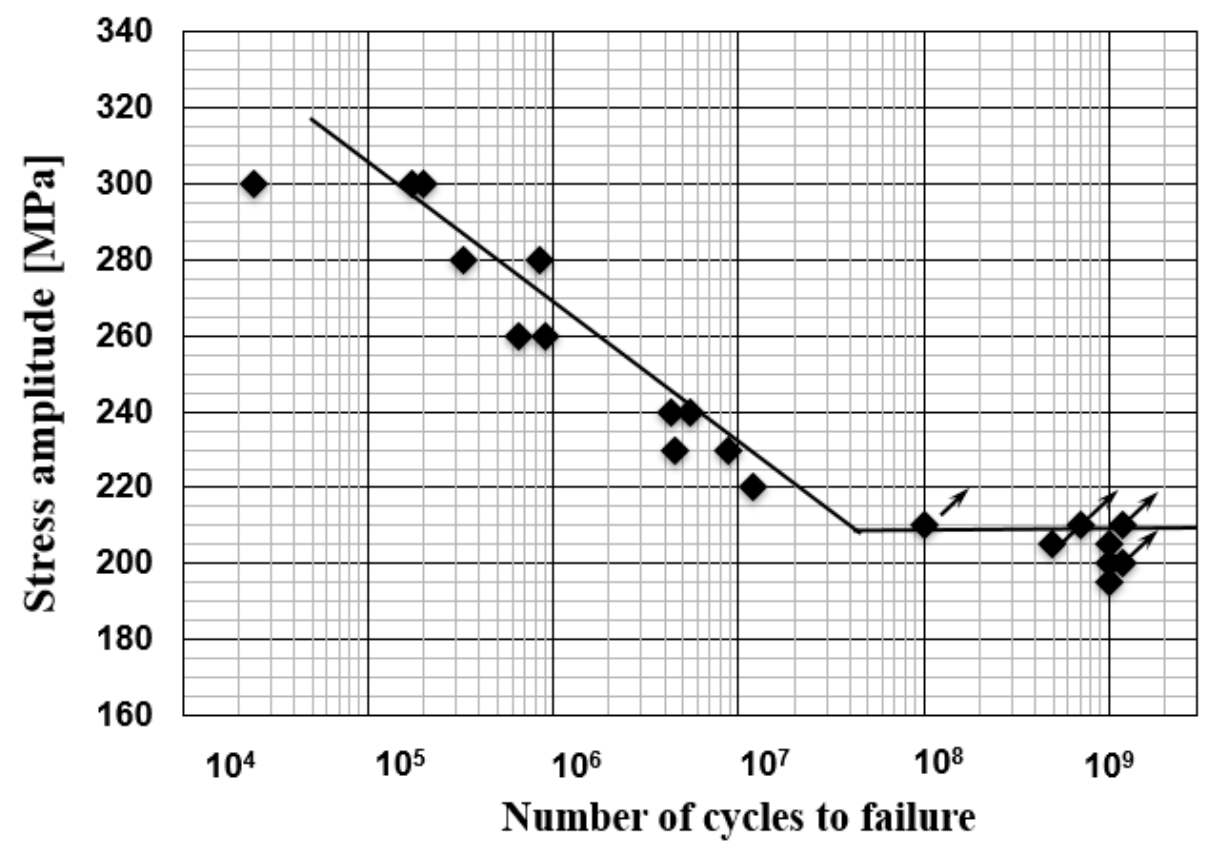

(a) S-N diagram at $-60^{\circ} \mathrm{C}$.

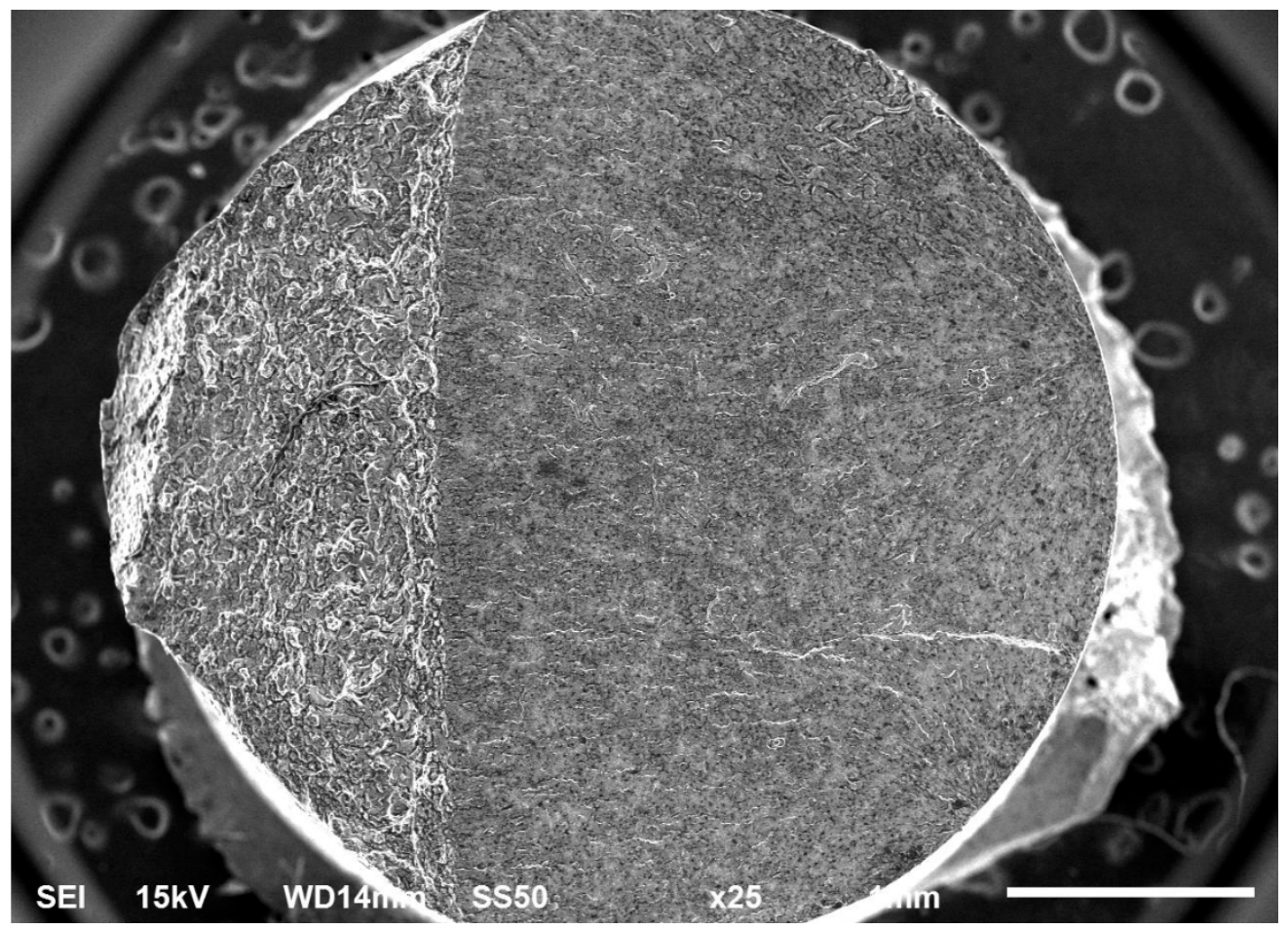

(b) Fracture surface at $-60^{\circ} \mathrm{C}, 280 \mathrm{MPa}, 840,000$ cycles.

Figure 8. Cont. 


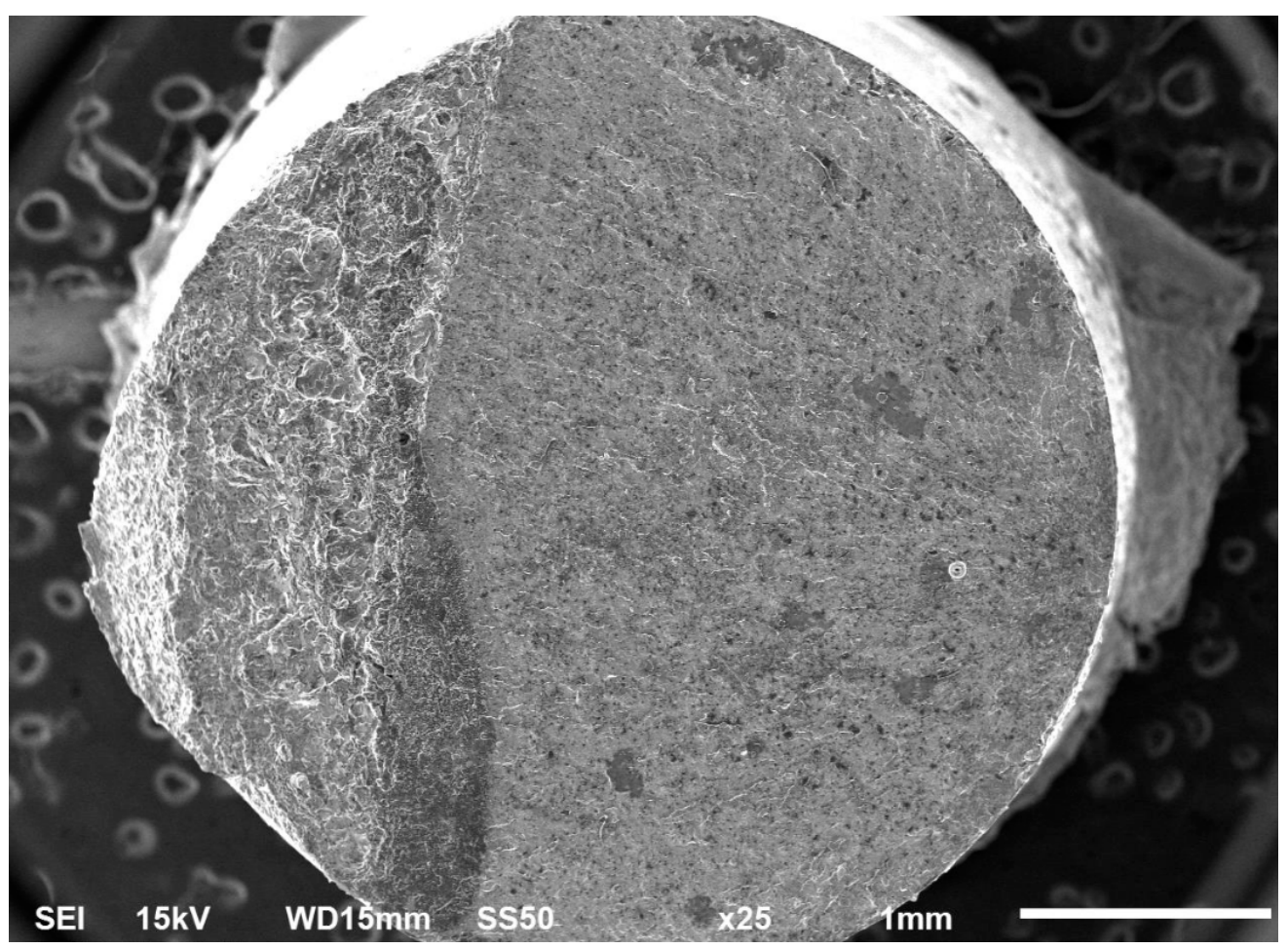

(c) Fracture surface at $-60^{\circ} \mathrm{C}, 240 \mathrm{MPa}, 5.5 \times 10^{6}$ cycles.

Figure 8. S-N diagram and fracture surface at $-60^{\circ} \mathrm{C}, 240 \mathrm{MPa}, \mathrm{Nf}=5.5 \times 10^{6}$ cycles.

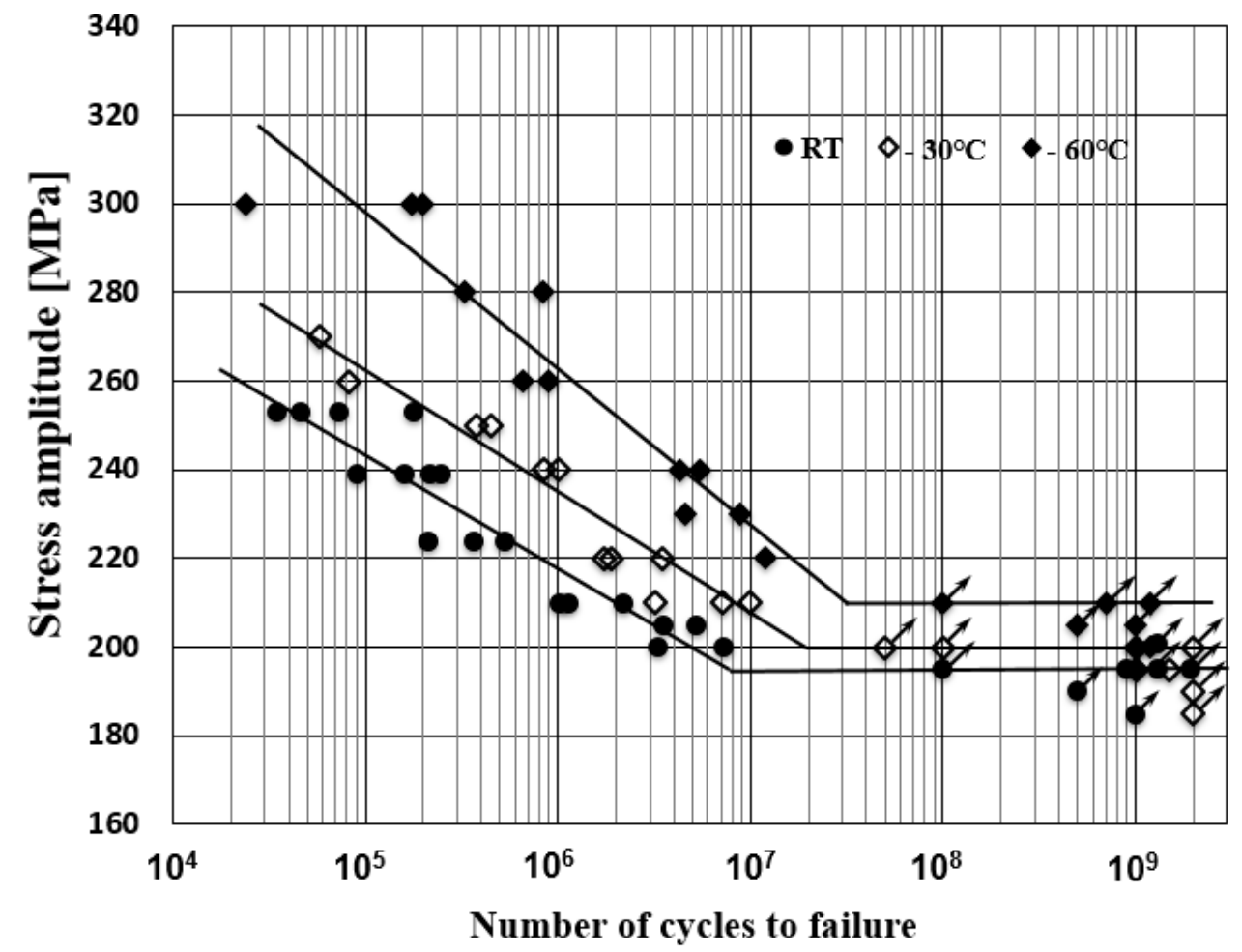

Figure 9. S-N diagram at room temperature $\left(\mathrm{RT}, 20^{\circ} \mathrm{C}\right),-30^{\circ} \mathrm{C}$, and $-60^{\circ} \mathrm{C}$.

\subsection{Charpy Impact Test}

Charpy impact testing was carried out in the temperature range of -60 to $+60{ }^{\circ} \mathrm{C}$, and the average value for the three specimens was taken at each temperature. Table 4 shows the brittle fracture 
appearance, lateral expansion, and impact absorption energy. The brittle fracture appearance is the ratio of the ductile area to the full fracture surface, which is inversely proportional to the impact absorption energy. Figure 10 shows the change in the shock absorption energy with temperature. At temperatures below $-30{ }^{\circ} \mathrm{C}$, full brittle fracture occurred. The three specimens exhibited nearly constant shock absorption energy. However, at temperatures above $-20^{\circ} \mathrm{C}$, along the edge of the fracture surface, ductile failure was observed. The shock absorption energies of the three specimens had slightly different values. Lateral expansion refers to the increase in the width of the specimen cross section measured in the groove direction after the test, which tends to be proportional to the impact absorption energy. According to the test results, the axle material became completely brittle in the range of -30 to $-40{ }^{\circ} \mathrm{C}$, and the shock-absorbing energy became very small, converging to a constant value. The minimum absorbed energy required by the KS standard [5] is $31 \mathrm{~J}$. The European EN standard [4] requires $30 \mathrm{~J}$ at $20^{\circ} \mathrm{C}$. The test results satisfied the two standards. Figure 11 shows fracture surfaces after the impact test. At cross sections below $-40{ }^{\circ} \mathrm{C}$, there were no ductile deformations (the slightly black areas near the edges). As the temperatures rose from $-30{ }^{\circ} \mathrm{C}$, the areas of ductile deformation near the edges of the specimens increased. Further, the deformation of the opposite edge of the groove increased. It was inferred from the low-temperature impact test data that the current axle material is vulnerable to external impacts at temperatures below $-30{ }^{\circ} \mathrm{C}$, which means that a defect can be easily caused by an external impact. Notably, the carbon steel axle used in this study did not contain alloying elements, such as $\mathrm{Cr}, \mathrm{Cu}, \mathrm{Mo}, \mathrm{Ni}$, and $\mathrm{V}$, included in the axle component of the EN standard [4]. It would be effective to add alloying elements to improve resistance to impact at low temperature. Figure 12 shows close-up images of the marked sites A and B in Figure 11a. Slides, cracks, and voids were observed, as shown in Figure 12a. When the temperature was increased to $60{ }^{\circ} \mathrm{C}$, ridges and dimples were observed, as shown in Figure $12 \mathrm{i}$.

Table 4. Charpy impact test results.

\begin{tabular}{cccccccccc}
\hline Temperature $\left({ }^{\circ} \mathrm{C}\right)$ & -60 & -50 & -40 & -30 & -20 & 0 & 20 & 40 & 60 \\
\hline $\begin{array}{c}\text { Brittle fracture } \\
\text { appearance }(\%)\end{array}$ & 100 & 100 & 100 & 90 & 90 & 80 & 70 & 40 & 50 \\
\hline Lateral expansion $(\mathrm{mm})$ & 0.05 & 0.03 & 0.06 & 0.17 & 0.22 & 0.34 & 0.67 & 0.87 & 1.24 \\
\hline $\begin{array}{c}\text { Impact absorption } \\
\text { energy }(\mathrm{J})\end{array}$ & 6.42 & 6.58 & 7.00 & 11.32 & 12.98 & 23.40 & 34.59 & 46.87 & 68.19 \\
\hline
\end{tabular}

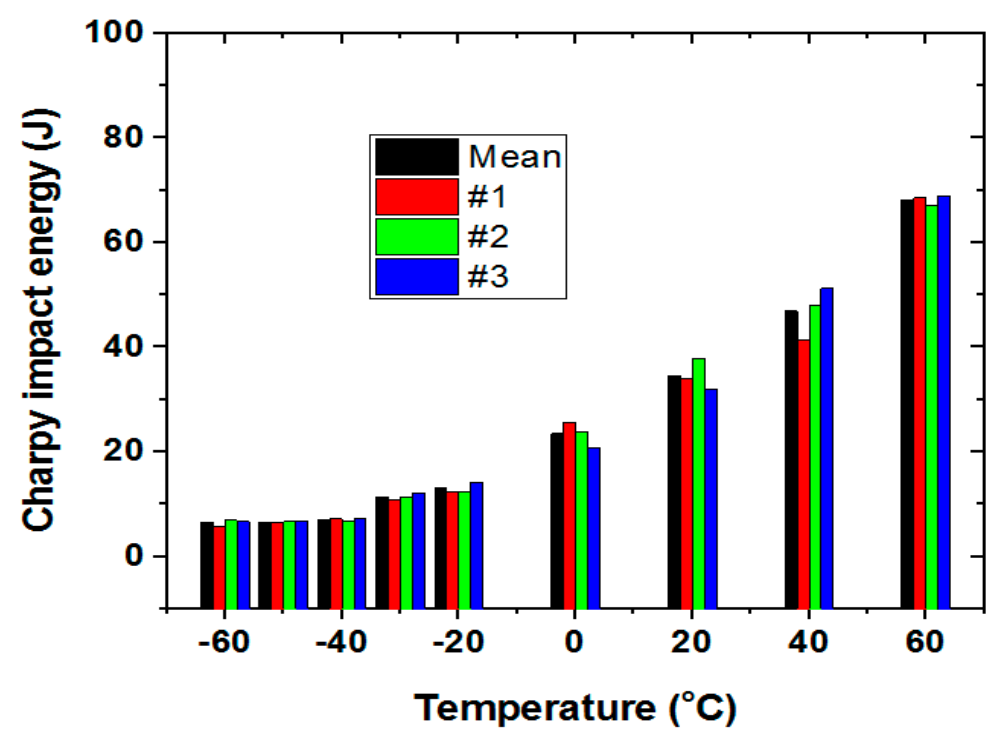

Figure 10. Charpy impact absorption energy. 


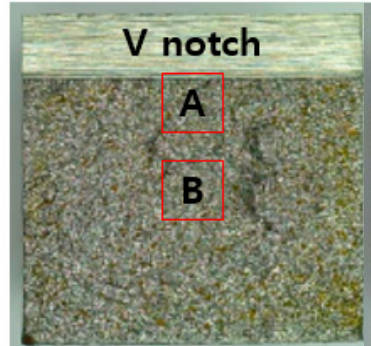

(a) $-60{ }^{\circ} \mathrm{C}$

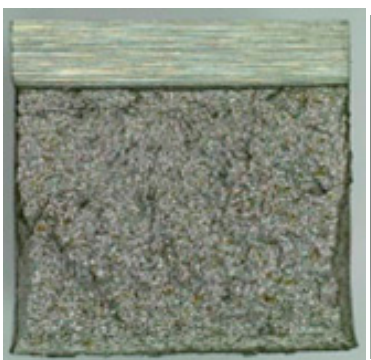

(e) $-20^{\circ} \mathrm{C}$

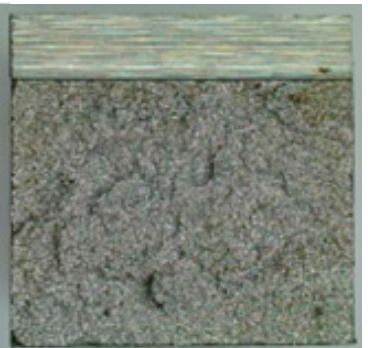

(b) $-50{ }^{\circ} \mathrm{C}$

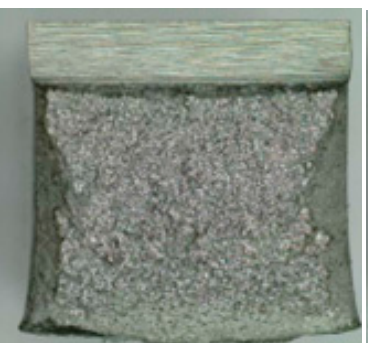

(f) $20^{\circ} \mathrm{C}$

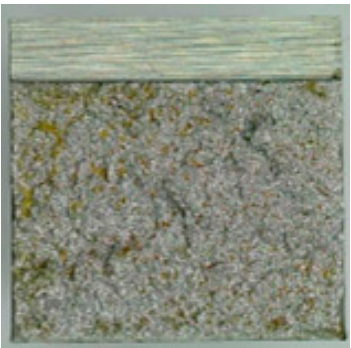

(c) $-40{ }^{\circ} \mathrm{C}$

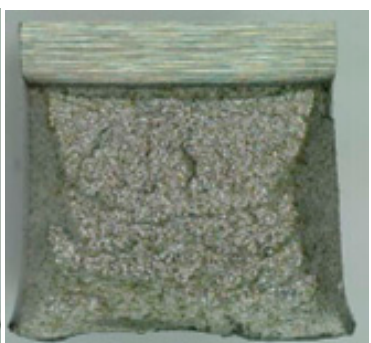

(g) $40{ }^{\circ} \mathrm{C}$

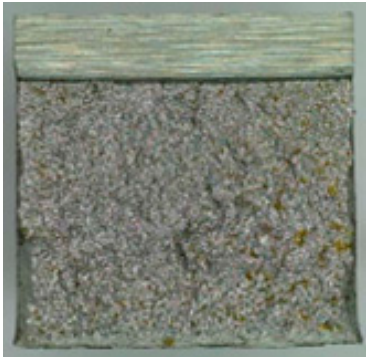

(d) $-30{ }^{\circ} \mathrm{C}$

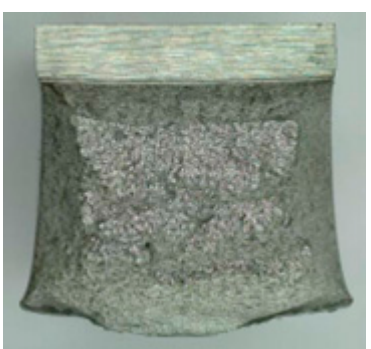

(h) $60^{\circ} \mathrm{C}$

Figure 11. Images of the fracture surfaces taken with an optical microscope.
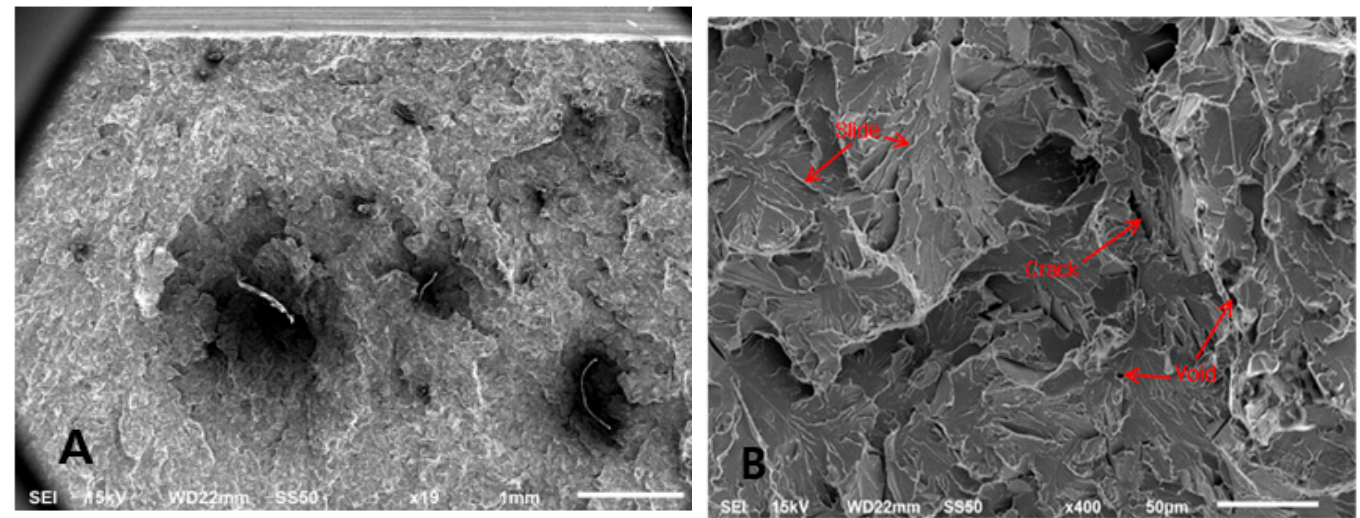

(a) Fracture surfaces of Charpy impact testing at $-60^{\circ} \mathrm{C}$.
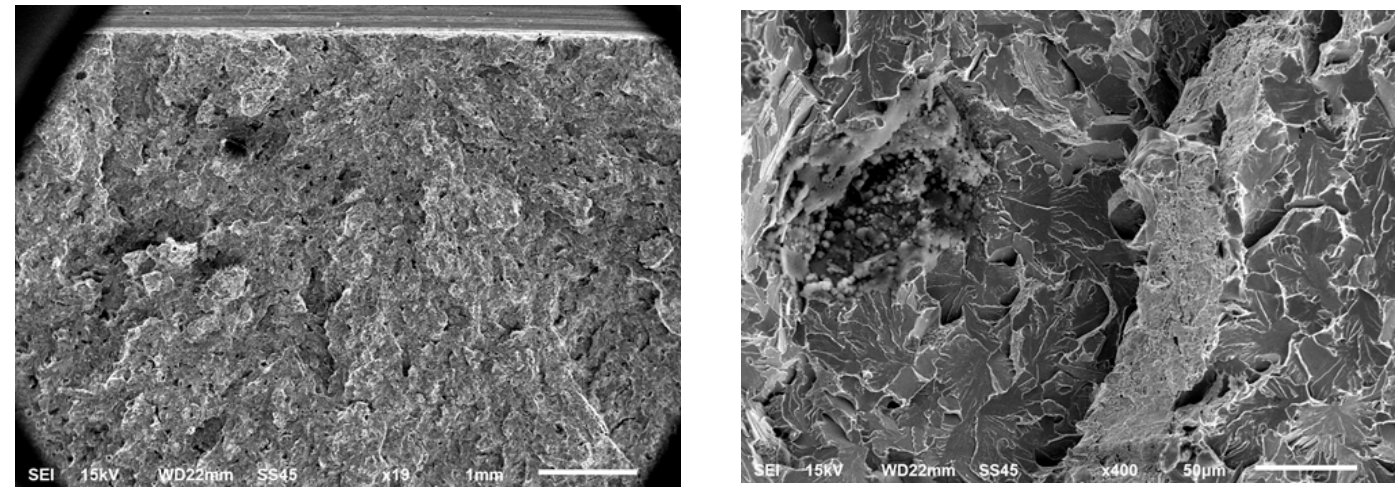

(b) Fracture surfaces of Charpy impact testing at $-50^{\circ} \mathrm{C}$.

Figure 12. Cont. 

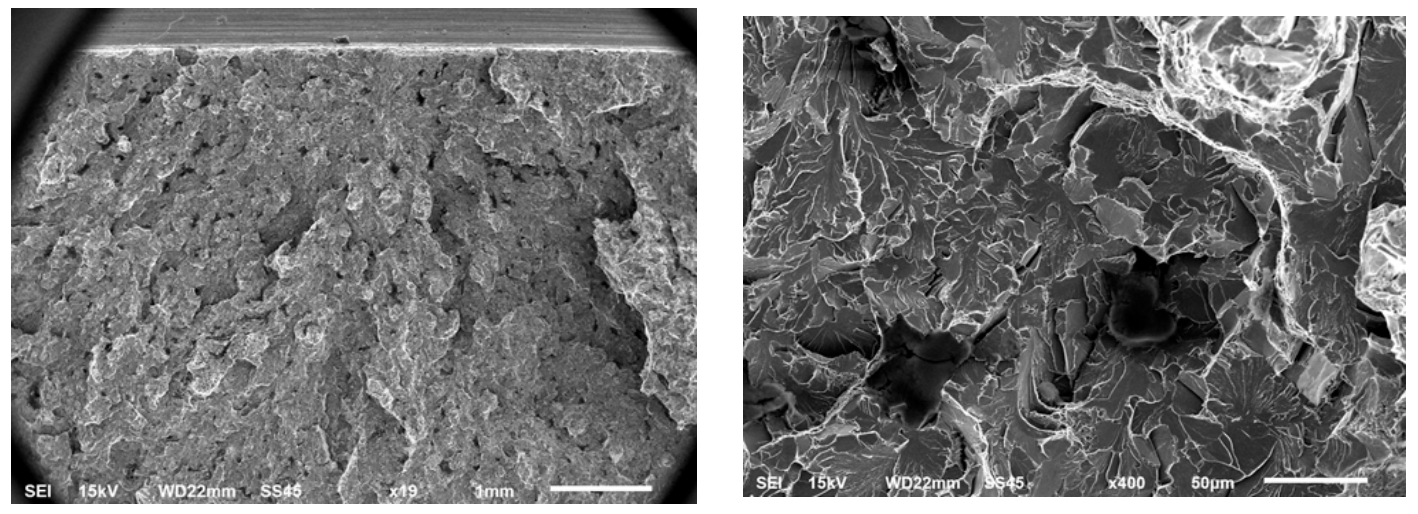

(c) Fracture surfaces of Charpy impact testing at $-40^{\circ} \mathrm{C}$.
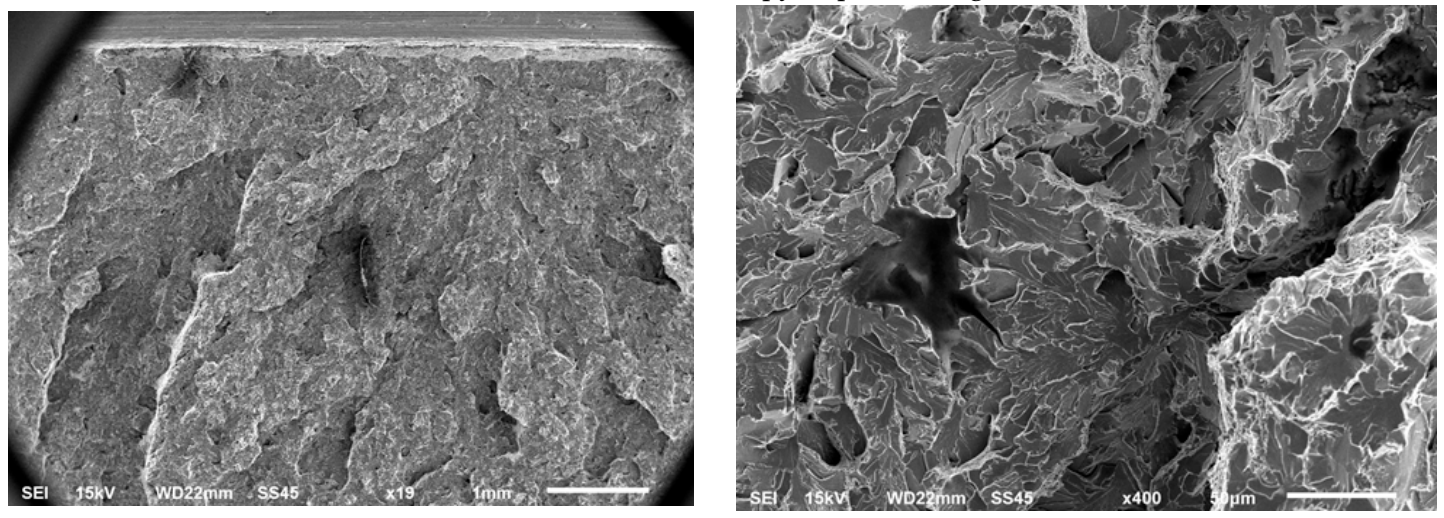

(d) Fracture surfaces of Charpy impact testing at $-30^{\circ} \mathrm{C}$.
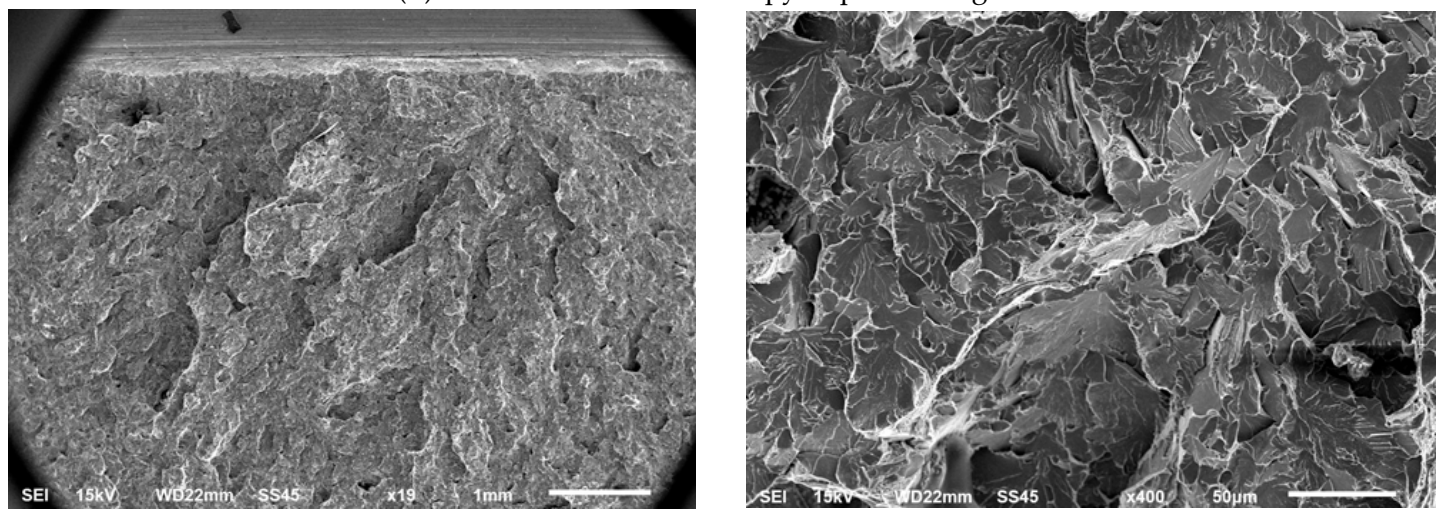

(e) Fracture surfaces of Charpy impact testing at $-20^{\circ} \mathrm{C}$.

Figure 12. Cont. 

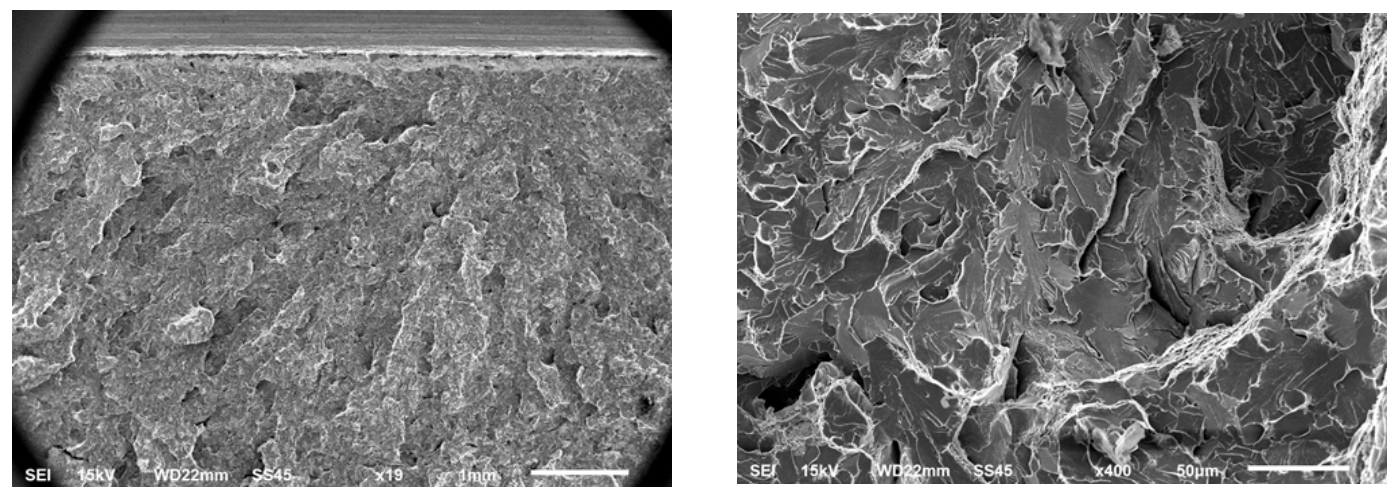

(f) Fracture surfaces of Charpy impact testing at $0{ }^{\circ} \mathrm{C}$.
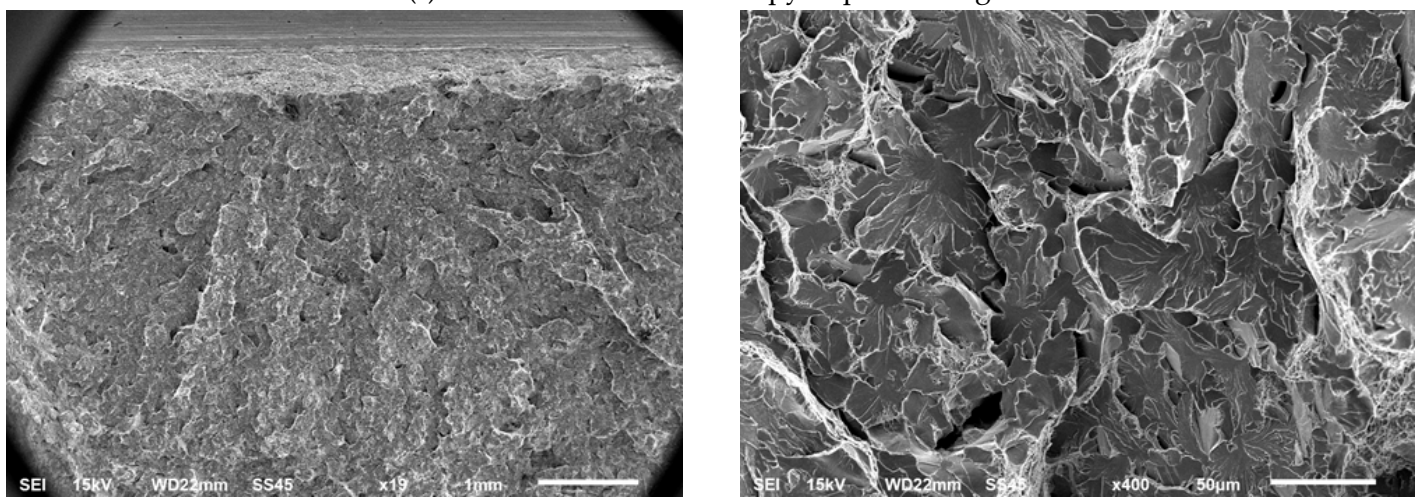

(g) Fracture surfaces of Charpy impact testing at $20^{\circ} \mathrm{C}$.
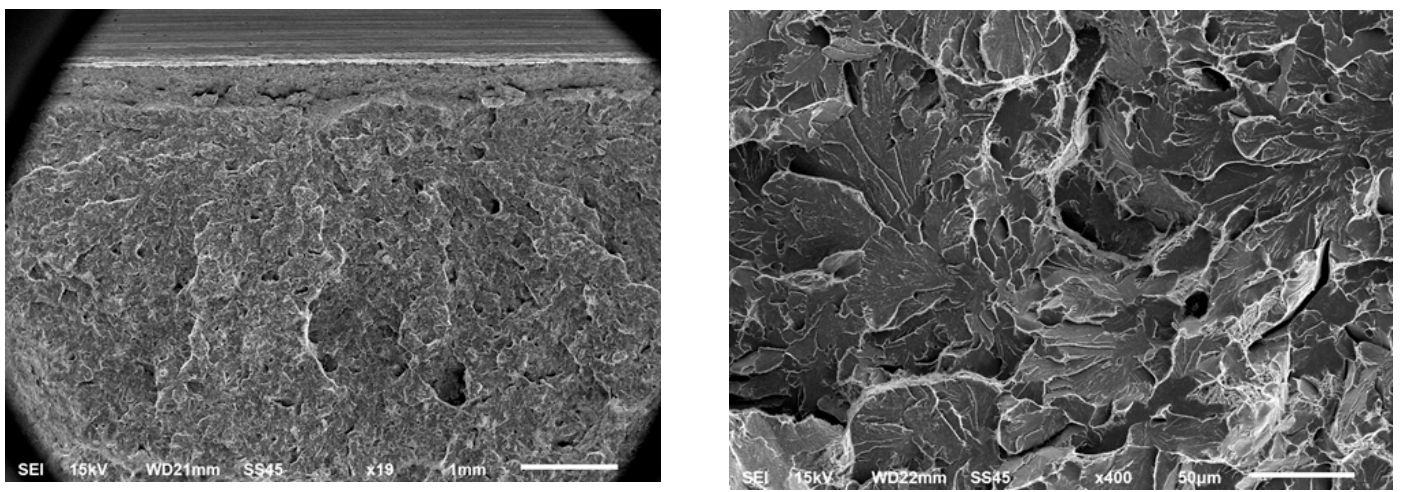

(h) Fracture surfaces of Charpy impact testing at $40^{\circ} \mathrm{C}$.
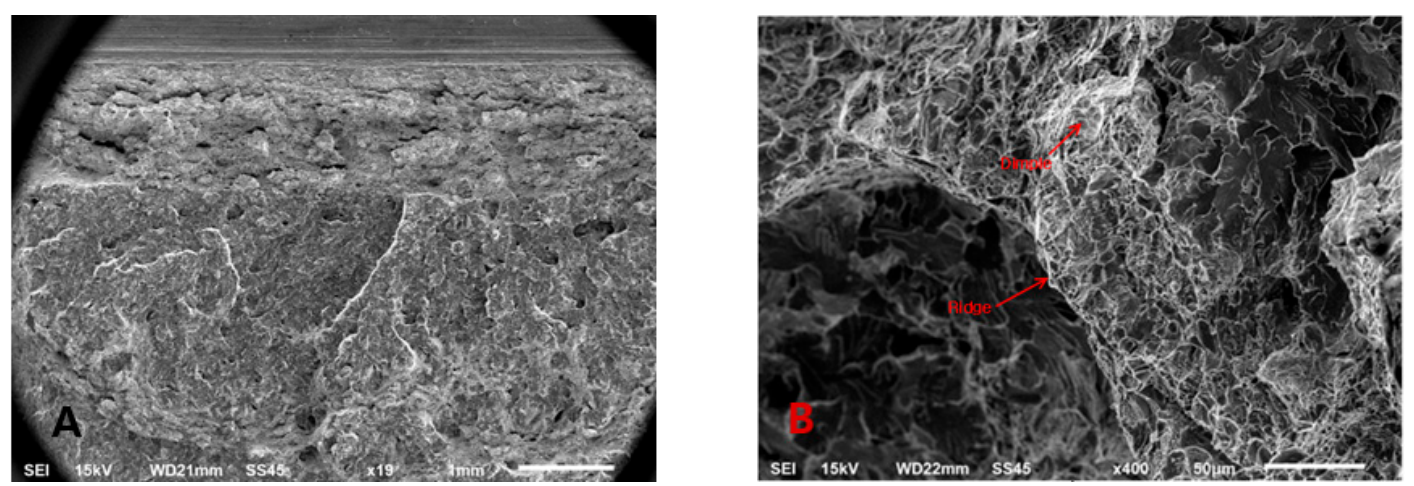

Figure 12. Cont. 

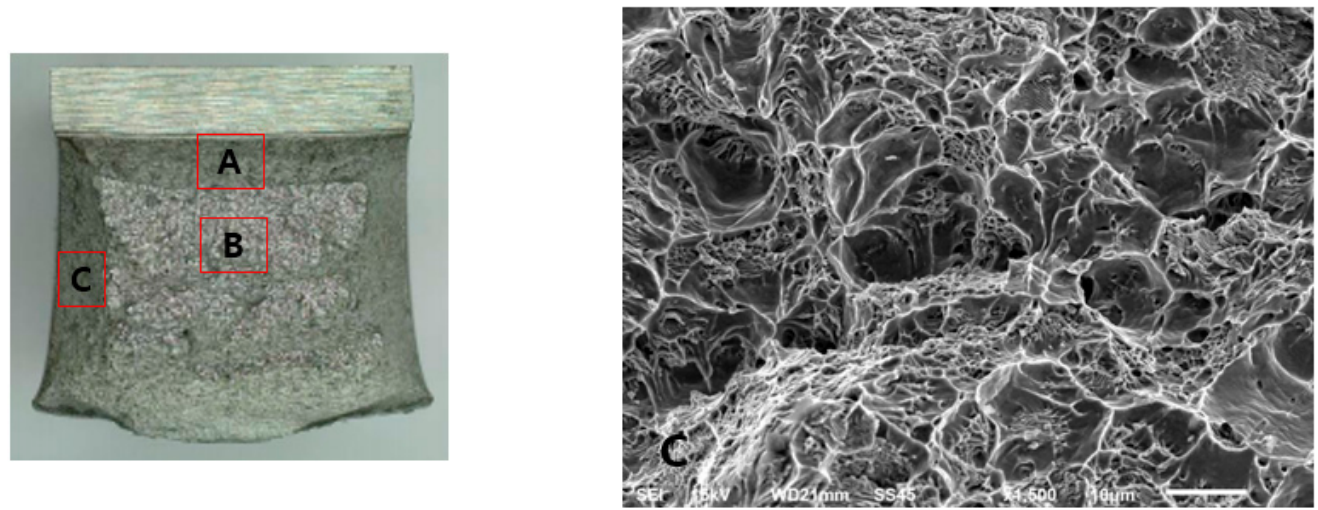

(i) Fracture surfaces of Charpy impact testing at $60^{\circ} \mathrm{C}$.

Figure 12. Images of fracture surfaces taken with a scanning electronic microscope.

\section{Conclusions}

In this study, specimens were produced from a commercial train axle made of manganese steel and subjected to high-cycle fatigue tests and Charpy impact tests over the temperature range of -60 to $60^{\circ} \mathrm{C}$ to obtain fatigue strength and impact absorption energy data about the axle material. Some important results were as follows.

A $20 \mathrm{kHz}$ ultrasonic actuator fatigue tester was successfully developed. It is capable of fatigue tests down to $-160^{\circ} \mathrm{C}$ by spraying liquid nitrogen into the chamber.

The fatigue strength values of the axle material at 2 million cycles at $+20,-30$, and, $-60{ }^{\circ} \mathrm{C}$ were $210.1,225.2$, and $251.9 \mathrm{MPa}$, respectively.

The fatigue strength of the axle material at -30 and $-60{ }^{\circ} \mathrm{C}$ increased by 7.1 and $19.9 \%$, respectively, compared to the fatigue strength at room temperature.

Fatigue failure occurred in the $2 \times 106$ to $1 \times 107$ cycle range, above the 2 million cycles traditionally considered to be the carbon steel fatigue limit.

The shock-absorbing energy of the axle material decreased gradually with decreasing temperature, and the axle material became fully brittle in the range of -30 to $-40{ }^{\circ} \mathrm{C}$. The shock absorption energy at $-60{ }^{\circ} \mathrm{C}$ was $81 \%$ lower than that at $20^{\circ} \mathrm{C}$. We inferred from the impact test results that the current axle material is vulnerable to external shocks at temperatures below $-30{ }^{\circ} \mathrm{C}$. These results suggest that it will be necessary to improve the low-temperature properties of the axle material used in this study for use in cold climates.

Author Contributions: Conceptualization and Methodology; Funding Acquisition, H.-S.M.; Analysis, Investigation, Data Curation, Writing - Original Draft and Editing, B.-C.G.; Ultrasonic Fatigue Testing, I.-S.C. All authors have read and agreed to the published version of the manuscript.

Funding: This study was supported by an R\&D program of Korea Railroad Research Institute.

Conflicts of Interest: The authors declare no conflict of interest.

\section{References}

1. Luo, R.; Teng, W.; Wu, X.; Shi, H.; Zeng, J. Dynamics simulation of a high-speed railway car operating in low-temperature environments with stochastic parameters. Veh. Syst. Dyn. 2019. [CrossRef]

2. Luo, R.; Shi, H.; Guo, J.; Huang, L.; Wang, J. A nonlinear rubber spring model for the dynamics simulation of a high-speed train. Veh. Syst. Dyn. 2019. [CrossRef]

3. Zerbst, U.; Beretta, S.; Köhler, G.; Lawton, A.; Vormwald, M.; Beier, H.T.; Klinger, C.; Černy, I.; Rudlin, J.; Heckel, T.; et al. Safe life and damage tolerance aspects of railway axles-A review. Eng. Fract. Mech. 2013, 98, 214-271. [CrossRef]

4. BS EN 13261:2009+A1:2010. Railway Applications-Wheelsets and Bogies-Axles-Product Requirements. BSI: London, UK. 
5. Korean Industrial Standards. Wheels for Railway Rolling Stock, KS R 9221; Korean Agency for Technology and Standards: Eumseonggun, Korea, 2008.

6. Ultrasonic Fatigue Testing. Mechanical Testing and Evaluation, ASM Handbook; ASM International: Novelty, OH, USA, 2000; Volume 8, pp. 717-728.

7. Bathias, C.; Paris, P.C. Gigacycle Fatigue in Mechanical Practice; Marcel Dekker: New York, NY, USA, 2005; pp. 9-29.

8. Stanzl-Tschegg, S. Very high cycle fatigue measuring techniques. Int. J. Fatigue 2014, 60, 2-17. [CrossRef]

9. Stanzl-Tschegg, S.E.; Mayer, H.R.; Tschegg, E.K. High frequency method for torsion fatigue testing. Ultrasonics 1993, 31, 275-280. [CrossRef]

10. Bathias, C. Piezoelectric fatigue testing machines and devices. Int. J. Fatigue 2006, 28, 1438-1445. [CrossRef]

11. Nikitin, A.; Bathias, C.; Palin-Luc, T. A new piezoelectric fatigue testing machine in pure torsion for ultrasonic gigacycle fatigue tests: Application to forged and extruded titanium alloys, Fatigue and Fracture of Engineering Materials \& Structures. Fatigue Fract. Eng. Mater. Struct. 2015, 38, 1294-1304.

12. Vieira, M.; Reis, L.; Freitas, M.; Ribeiro, A. Strain measurements on specimens subjected to biaxial ultrasonic fatigue testing. Theor. Appl. Fract. Mech. 2016, 85, 2-8. [CrossRef]

13. Costa, P.; Vieira, M.; Reis, L.; Ribeiro, A.; Freitas, M. New specimen and horn design for combined tension and torsion ultrasonic fatigue testing in the very high cycle fatigue regime. Int. J. Fatigue 2017, 103, 248-257. [CrossRef]

14. Wang, Q.Y.; Berard, J.Y.; Rathery, S.; Bathias, C. High-cycle fatigue crack initiation and propagation behaviour of high-strength spring steel wires. Fatigue Fract. Eng. Mater. Struct. 1999, 22, 673-677. [CrossRef]

15. Wang, Q.Y.; Bathias, C.; Kawagoishi, N.; Chen, Q. Effect of inclusion on subsurface crack initiation and gigacycle fatigue strength. Int. J. Fatigue 2002, 24, 1269-1274. [CrossRef]

16. Ochi, Y.; Matsumura, T.; Masaki, K.; Yoshida, S. High-cycle rotating bending fatigue property in very long-life regime of high-strength steels. Fatigue Fract. Eng. Mater. Struct. 2002, 25, 823-830. [CrossRef]

17. Murakami, Y.; Endo, M. Effects of defects, inclusions and inhomogeneities on fatigue strength. Int. J. Fatigue 1994, 16, 163-182. [CrossRef]

18. Murakami, Y.; Takada, M.; Toriyama, T. Super-long life tension-compression fatigue properties of quenched and tempered $0.46 \%$ carbon steel. Int. J. Fatigue 1998, 16, 661-667. [CrossRef]

19. Zettl, B.; Mayer, H.; Ede, C.; Stanzl-Tschegg, S. Very high cycle fatigue of normalized carbon steels. Int. J. Fatigue 2006, 28, 1583-1589. [CrossRef]

20. Zhao, Y.X.; Yang, B.; Feng, M.F.; Wang, H. Probabilistic fatigue $S-N$ curves including the super-long life regime of a railway axle steel. Int. J. Fatigue 2009, 31, 1550-1558. [CrossRef]

21. Qian, G.; Zhou, C.; Hong, Y. Crack propagation mechanism and life prediction for very-high cycle fatigue of a structural steel in different environmental medias. Frat. Integrità Strutt. 2013, 25, 7-14. [CrossRef]

22. Wu, W.; Zhu, M.L.; Liu, X.; Xuan, F.G. Effect of temperature on high-cycle fatigue and very high cycle fatigue behaviour of a low-strength $\mathrm{Cr}-\mathrm{Ni}-\mathrm{Mo}-\mathrm{V}$ steel welded joint. Fatigue Fract. Eng. Mater. Struct. 2017, 40, 45-54. [CrossRef]

(C) 2020 by the authors. Licensee MDPI, Basel, Switzerland. This article is an open access article distributed under the terms and conditions of the Creative Commons Attribution (CC BY) license (http://creativecommons.org/licenses/by/4.0/). 